University of Wollongong

Research Online

Faculty of Engineering - Papers (Archive)

Faculty of Engineering and Information

Sciences

$12-6-2012$

\title{
Microstructure evolution and alloying elements distribution between the phases in powder near-b titanium alloys during thermo-mechanical processing
}

\author{
Mansur Ahmed \\ University of Wollongong, ma960@uowmail.edu.au \\ Azdiar A. Gazder \\ University of Wollongong, azdiar@uow.edu.au \\ Dmytro G. Savvakin \\ National Academy of Sciences, Ukraine \\ Orest M. Ivasishin \\ National Academy of Sciences, Ukraine \\ E V. Pereloma \\ University of Wollongong, elenap@uow.edu.au
}

Follow this and additional works at: https://ro.uow.edu.au/engpapers

Part of the Engineering Commons

https://ro.uow.edu.au/engpapers/5323

\section{Recommended Citation}

Ahmed, Mansur; Gazder, Azdiar A.; Savvakin, Dmytro G.; Ivasishin, Orest M.; and Pereloma, E V.:

Microstructure evolution and alloying elements distribution between the phases in powder near-b titanium alloys during thermo-mechanical processing 2012, 7013-7025.

https://ro.uow.edu.au/engpapers/5323 


\title{
Microstructure evolution and alloying elements distribution between the phases in powder near- $\beta$ titanium alloys during thermo-mechanical processing
}

\author{
Mansur Ahmed $^{1^{*}}$, Azdiar A. Gazder ${ }^{1}$, Dmytro G. Savvakin², Orest M. Ivasishin², Elena V. \\ Pereloma $^{1}$ \\ ${ }^{1}$ School of Mechanical, Materials \& Mechatronic Engineering, University of Wollongong, Wollongong, NSW- \\ 2522, Australia \\ ${ }^{2}$ Institute for Metal Physics, National Academy of Sciences Ukraine, UA-03142 Kiev, Ukraine
}

Key words: powder titanium, thermo-mechanical processing, microstructure, alloying elements.

Abstract:

In the present study, two powder near- $\beta$ Ti alloys having a nominal composition of Ti-5Al-5Mo-5V-XCr-1Fe (X=1-2, wt.\%) were studied. The alloys were produced via the blended elemental powder metallurgy technique using hydrogenated Ti powder. Microstructure evolution and the distribution of the alloying elements between the phases were investigated after each step of thermo-mechanical processing (TMP). Microstructures were refined through the TMP in both alloys. Porosity was reduced with deformation at $1173 \mathrm{~K}\left(900^{\circ} \mathrm{C}\right)$ in the $\beta$ phase field. The $\beta \rightarrow \alpha$ phase transformation occurred during soaking at $1023 \mathrm{~K}\left(750^{\circ} \mathrm{C}\right)$ in the $\alpha+\beta$ phase field. Fragmentation of the continuous grain boundary $\alpha$ occurred by the $40 \%$ deformation at $1023 \mathrm{~K}\left(750^{\circ} \mathrm{C}\right)$. Variation in the concentration of the alloying elements in each phase took place through the diffusion during soaking in the $\alpha+\beta$ phase field, e.g. exit of $\beta$-stabilisers from the $\alpha$-phase. However, the $\alpha$ phase remained supersaturated with $\beta$ stabilisers. Deformation had no influence on the distribution of the alloying elements. An additional $1 \% \mathrm{Cr}$ content slightly affects on the amount of the $\alpha$ phase formed and $\beta$ grain size, but has no noticeable effect on the distribution of the alloying elements between the phases.

\footnotetext{
Tel: +61 242215798

Fax: +61 242213662
}

*Corresponding Author: Mansur Ahmed (ma960@uowmail.edu.au) 


\section{INTRODUCTION:}

Near $\beta$-Ti alloy VT22 and its modified compositions are used for aerospace applications in landing gear parts (for example, as bogie beams and lower and upper torque links) and in the compressor of aero-engines due to their high strength (1100-1260 MPa) and fracture toughness (66-77 MPa $\mathrm{m}^{1 / 2}$ ), reasonably good ductility (8-14\%), favourable fatigue strength as well as corrosion resistance properties [1, 2]. In order to increase the affordability of titanium alloys through reduction in production costs, near net shape powder metallurgy techniques are fast becoming the most preferred production route compared to conventional techniques. This is mainly because powder metallurgy based processes return significantly higher material yield by minimising waste [3,4]. Among the powder metallurgy methods for Ti alloy production, the blended elemental powder metallurgy (BEPM) technique is regarded as the most cost effective one which can produce alloy having high density with a uniform distribution of the alloying elements throughout the matrix after sintering $[5,6]$. If the BEPM is undertaken with Ti powder only, then an additional hot isostatic pressing (HIP) step is necessary to achieve high density after sintering. On the other hand, if hydrogenated Ti powder is used in BEPM, then additional HIP step is not required. Thus, the production cost can be reduced further. Ivasishin et al. [7] produced Ti-6Al-4V alloy via the BEPM technique using hydrogenated Ti powder without any additional HIP step and obtained a high density ( 99\%) in the powder alloy after sintering.

In general, near- $\beta$ Ti alloys respond to heat treatment, such that the grain boundary $\alpha\left(\alpha_{\mathrm{GB}}\right)$ phase, the inter-granular and intra-granular $\alpha$ phase, and the $\beta$ grains are the microstructural constituents obtained through thermo-mechanical processing (TMP). The size, shape and amount of the various phases can be modified by varying the TMP parameters. Sauer and Luetjering [8] utilised various processing schedules to achieve microstructures in two high strength $\beta$-alloys, $\beta$-CEZ and Ti-6246. They produced a bimodal microstructure using a TMP technique known as $\alpha+\beta$ processing. The schedule involved $\beta$ annealing treatment, hot deformation in the $\alpha+\beta$ two phase field followed by a holding in the $\alpha+\beta$ phase field. During the cooling to room temperature from the $\beta$-annealing temperature and the heating to $\alpha+\beta$ hot deformation temperature from room temperature, large equiaxed $\beta$ grains surrounded by a continuous $\alpha$ phase were produced. The plastic deformation in the $\alpha+\beta$ phase field produced dislocation density which serve as nucleation site of $\alpha$ phase during subsequent cooling to room temperature. Thereafter, the $\alpha+\beta$ holding produced acicular $\alpha$ phase by $\beta \rightarrow \alpha$ phase transformation. However, the above mentioned $\alpha+\beta$ processing produced a microstructure comprising of equiaxed $\beta$ grains along with continuous $\alpha$ phase and acicular $\alpha$ phase. The continuous grain boundary $\alpha$ surrounding the $\beta$ grains is deleterious for ductility due to the strain is localised in the continuous $\alpha$ leading to crack nucleation and fractures at grain boundaries [9-11]. In order to minimise the effect of continuous grain boundary $\alpha$, Clement et al. [10] suggested two possible preventive measures which are: (i) to apply $\alpha+\beta$ hot forging to the alloy after holding in the $\alpha+\beta$ phase field (ii) to apply cold forging prior to ageing. Weiss and Semiatin [12] reported that the $\alpha+\beta$ hot deformation should be performed while the volume fraction of the $\alpha$ phase is $\leq 30 \%$.

There are very few findings on the distribution of the alloying elements between the phases ( $\alpha$ and $\beta$ ) during TMP. The distribution of the alloying elements depends on their solubility, diffusion rate, as well as the time allowed for diffusion to take place. Nag et al. [13] studied elemental partitioning between the $\alpha$ and $\beta$ phases in Ti-5Al-5Mo-5V-3Cr alloy. Using 3D atom probe tomography, they found that all the alloying elements partitioned pronouncedly between the phases during sub-transus annealing through the diffusion of the alloying elements. Mo piled-up more at the interfaces due to its slow diffusivity than other alloying elements during step-quenching to $973 \mathrm{~K}\left(700^{\circ} \mathrm{C}\right)$ and holding for 1800 s which can play a vital role in growth kinetics of $\alpha$ phase. 
In this work, a traditional Ti-5Al-5Mo-5V-1Cr-1Fe (VT22) alloy was chosen as it is produced via the cost effective BEPM method using powder for the first time and a modified VT22 (Ti-5Al-5Mo-5V-2Cr-1Fe) alloy was also selected since the Cr content controls the grain size during heat treatment in the $\beta$ phase field [14], as well as reduces the amount of $\alpha$ phase $[15,16]$ formed during soaking in the $\alpha+\beta$ phase field resulting in improved ductility [17]. However, if more $\mathrm{Cr}(\geq 2$ wt. $\%)$ is added to the alloy, the Mo equivalent is further increased $\left(\mathrm{Mo}_{\text {eq. }}=1 \times \mathrm{Mo}+0.67 \times \mathrm{V}+1.6 \times \mathrm{Cr}+2.9 \times \mathrm{Fe}-\right.$ $1 \times \mathrm{Al}$, the amount which determines the $\beta$ stability of the alloy). The greater Mo equivalent results in steeper $\beta$ transus gradient, which makes the processing window narrow and more difficult to control [18]. The aim of the present study is to examine the microstructure evolution and the distribution of the alloying elements between the phases of two near- $\beta$ $\mathrm{Ti}$ alloys during thermo-mechanical processing. The nominal composition of the alloys are Ti-5Al-5Mo-5V-XCr-1Fe (X=1-2) (in wt. \%). The two alloys will hereafter be referred to as Ti-55511 and Ti-55521 alloy, respectively throughout the text. Other objectives include reducing the harmful effect of the continuous grain boundary $\alpha$ and to understand the effect of additional Cr content in Ti-55521 alloy.

\section{MATERIALS AND EXPERIMENTAL PROCEDURE:}

Hydrogenated Ti powder containing 3.5 wt.\% hydrogen was blended with 50Al-50V (wt.\%) master alloy powder and Mo, Cr, Fe elemental powders to achieve the desired composition of the Ti-5Al-5Mo-5V-1Cr-1Fe (Ti-55511) and Ti5Al-5Mo-5V-2Cr-1Fe (Ti-55521) alloys. The size of all the alloying elements powders was less than $40 \mu \mathrm{m}$ with the exception of Mo (40-63 $\mu \mathrm{m})$. Thereafter, the blended powders were die pressed at room temperature under a pressure of 650MPa to form bar-shaped green compacts. The compacts were then sintered in two steps comprising heating at 1293 $\mathrm{K}\left(1020^{\circ} \mathrm{C}\right)$ for 3600 s followed by heating at $1523 \mathrm{~K}\left(1250^{\circ} \mathrm{C}\right)$ for 21600 s. The average compositions (in wt.\%) of the two as-sintered alloys determined by Energy dispersive Spectroscopy (EDS) are given in Table 1.

Cylindrical samples with a diameter of $4 \mathrm{~mm}$ and length of $6 \mathrm{~mm}$ were machined from the sintered bars. A Gleeble 3500 thermo-mechanical simulator in pocket jaw mode was employed for the TMP of both alloys. A K-type thermocouple (a combination of Chromel and Alumel) was spot welded to the specimens at their longitudinal midpoint. The specimens were placed between copper jaws and resistance heated. The entire TMP schedule (Figure 1) was conducted in a vacuum of $3.8 \times 10^{-4}$ torrs in order to prevent high temperature oxidation and atmospheric contamination. The samples for analysis were water quenched after four steps of the TMP schedule described below:

(i) Step I: heating at $10 \mathrm{Ks}^{-1}$ to $1223 \mathrm{~K}\left(950^{\circ} \mathrm{C}\right)$, hold for $120 \mathrm{~s}$

(ii) Step II: Step I + Cooling at $35 \mathrm{Ks}^{-1}$ from $1223 \mathrm{~K}\left(950^{\circ} \mathrm{C}\right)$ to $1173 \mathrm{~K}\left(900^{\circ} \mathrm{C}\right)$ where $25 \%$ deformation took place

(iii) Step III: Step II + Cooling at $35 \mathrm{Ks}^{-1}$ from $1173 \mathrm{~K}\left(900^{\circ} \mathrm{C}\right)$ to $1023 \mathrm{~K}\left(750^{\circ} \mathrm{C}\right), 1800$ s soaking

(iv) Step IV: Step III + 40\% deformation at $1023 \mathrm{~K}\left(750^{\circ} \mathrm{C}\right)$.

In addition, the $5^{\text {th }}$ sample was processed similar to the one after step III, but with $40 \%$ deformation at $1173 \mathrm{~K}\left(900^{\circ} \mathrm{C}\right)$. This schedule is termed Step III(a) hereafter.

The samples of both alloys were prepared for metallography after cutting perpendicular to the deformation direction. Then the samples were hot mounted under a pressure of $7.17 \mathrm{MPa}$ at $423 \mathrm{~K}\left(150^{\circ} \mathrm{C}\right)$ for $480 \mathrm{~s}$. The mounted samples were rough ground using 500 and $1200 \mathrm{SiC}$ papers, fine ground with a $15 \mu \mathrm{m}$ diamond disk followed by fine polishing with colloidal silica suspension. Thereafter, the polished samples were etched to reveal the microstructures using

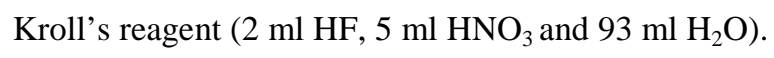


A JEOL JSM 7001F Field Emission Gun - Scanning Electron Microscope (FEG-SEM), equipped with a 127eV Bruker-AXS XFlash detector Energy Dispersive X-ray spectroscopy (EDS) system, was used for semiquantitative compositional analysis to find out the variation in the concentration between the phases. The accelerating voltage

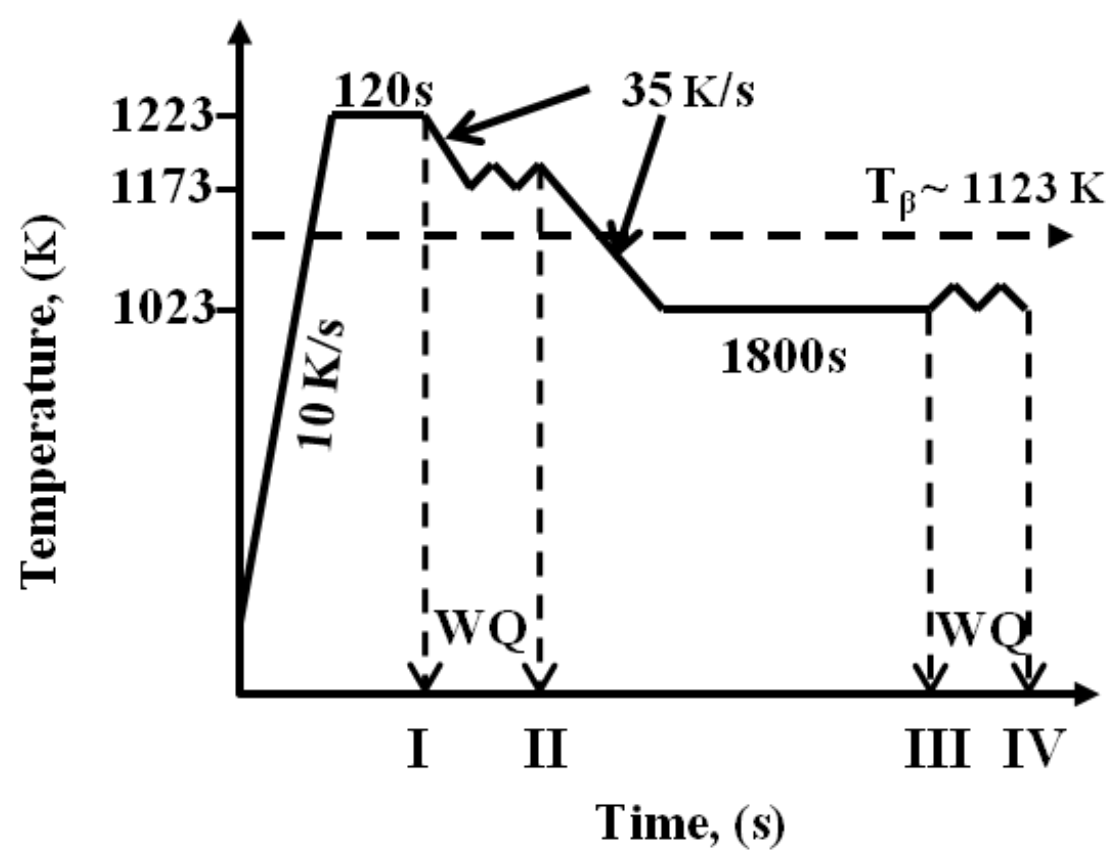

Figure 1: A schematic illustration of the thermo-mechanical processing schedule employed in the present study.

was $15 \mathrm{kV}$ and a probe current was chosen to provide an EDX count rate of approximately $25 \mathrm{kcps}$, so as to ensure good statistics. $X$-ray maps were then acquired for 14.4ks using an image resolution of $1200 \times 1024$ pixels and a dwell time of $12 \mathrm{~ms}$. The $\mathrm{X}$-ray line scans were then analysed in the $\mathrm{X}$-ray maps using an interactive standard-less PB-ZAF analysis whereby the elements were set and an appropriate Bremsstrahlung background was selected in order to obtain an optimum fit before quantification was performed. The accuracy of the compositional measurement was $\pm 5 \%$. At least $30 \mathrm{X}$-ray line scans were performed for each phase composition whereas each $\mathrm{x}$-ray line scan was a combination of numerous points. Moreover, the EDS spectra did not overlap. Back scattered electron (BSE) mode was used for microstructure imaging. The porosity and area fraction of the different phases of both alloys was measured using secondary electron images of the microstructures and MATLAB image processing program. The $\beta$ grain size and the width of the grain boundary $\alpha$ was measured using Image Tool 3.0 software.

\section{RESULTS}

\subsection{Microstructure Characterisation:}

3.1.1. Microstructure of the as-sintered material: 
The BSE microstructures of the as-sintered samples for the two alloys are shown in Figure 2. Three types of $\alpha$ phase were present in the microstructure of the as-sintered alloys: (i) a grain boundary $\alpha$ phase, (ii) an intra-granular $\alpha$ phase that nucleates and grows inside the $\beta$ grains and, (iii) an inter-granular $\alpha$ phase that nucleates from the grain boundary $\alpha$ phase and grows into the $\beta$ grains. For the purposes of this study, the intra-granular and inter-granular $\alpha$ phases are collectively termed as the " $\alpha$ phase" throughout the text. In the as-sintered samples, the width of the grain boundary $\alpha$ phase was $2.58 \pm 1.34 \mu \mathrm{m}$ in the Ti-55511 alloy and $2.52 \pm 0.65 \mu \mathrm{m}$ in the Ti-55521 alloy. The grain boundary $\alpha$ phase around the $\beta$ grain was continuous in both alloys. The average $\beta$ grain size for the Ti-55511 alloy was $74 \pm 17 \mu \mathrm{m}$ and $70 \pm 14 \mu \mathrm{m}$ for the Ti-55521 alloy, respectively. Both alloys still contained $\sim 2 \%$ porosity in the as-sintered form.

\subsubsection{Microstructure after annealing and deformation in the $\beta$ phase field:}

The BSE microstructures of the Ti-55511 and Ti-55521 near- $\beta$ Ti alloys after annealing at $1223 \mathrm{~K}\left(950^{\circ} \mathrm{C}\right)$ for $120 \mathrm{~s}$ (step I) and $25 \%$ deformation at $1173 \mathrm{~K}\left(900^{\circ} \mathrm{C}\right)$ (step II) are shown in Figure 3 . Tables 2 and 3 indicate the area fraction of the porosity and all the constituent phases,

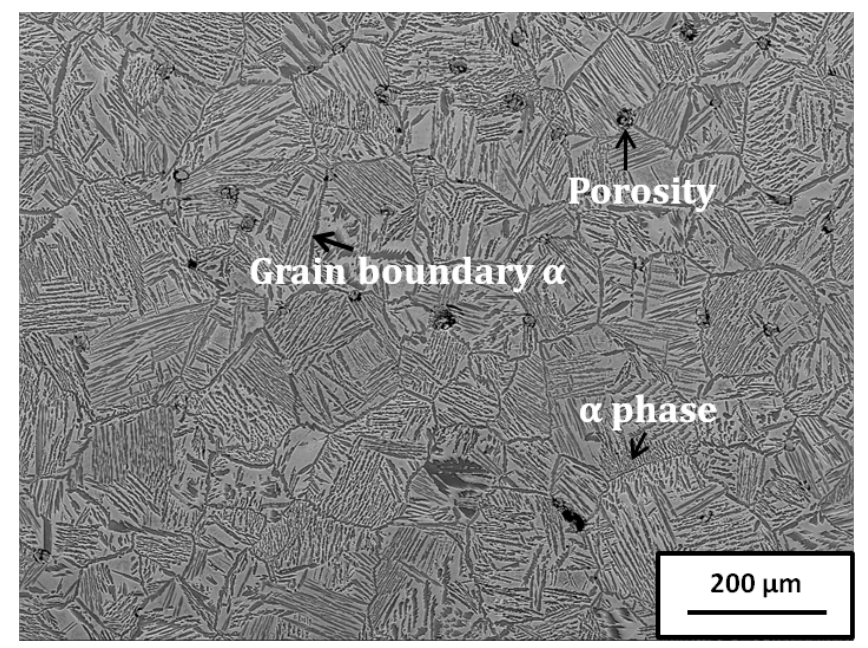

(a)

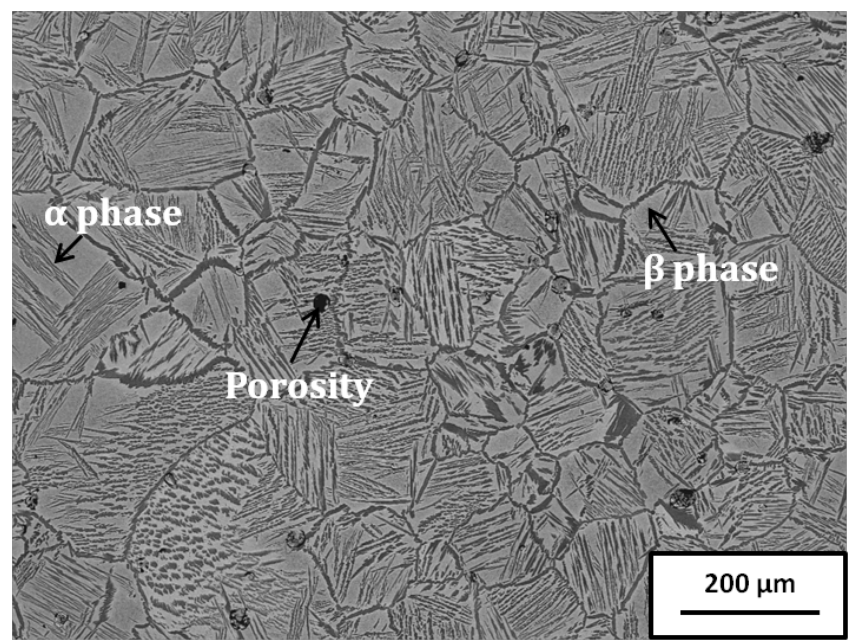

(b)

Figure 2: Back-scattered electron images of the as-sintered microstructures of (a) Ti-5Al-5Mo-5V1Cr-1Fe (Ti-55511) and (b) Ti-5Al-5Mo-5V-2Cr-1Fe (Ti-55521) alloy. The $\alpha$ phase in Figure 2 (a) indicates inter-granular $\alpha$ and the $\alpha$ phase in Figure 2 (b) indicates intra-granular $\alpha$.

the width of the grain boundary $\alpha$ phase as well as the average $\beta$ grain size of the Ti-55511 and Ti-55521 alloys, respectively after each TMP step. Since the appearance of a wide and continuous grain boundary $\alpha$ phase is deleterious for ductility [9-11], this was partially negated by near dissolution of the $\alpha$ phase during annealing for 120 s at $1223 \mathrm{~K}$ $\left(950^{\circ} \mathrm{C}\right)$, which is above the $\beta$-transus temperature $\left(\sim 1123 \mathrm{~K}\left(850^{\circ} \mathrm{C}\right)\right.$ for the Ti-55511 alloy [19]). Prolonged heating at the super-transus temperature was deliberately avoided in order to minimise the coarsening of the $\beta$ grains. The area fraction of the porosity after $\beta$-annealing was $1.9 \%$ for the Ti-55511 alloy and $1.7 \%$ for the Ti-55521 alloy, respectively. As a result of annealing in the $\beta$ phase field during Step I, the average $\beta$ grain size was $73 \pm 12 \mu \mathrm{m}$ in the Ti-55511 alloy and $68 \pm 9 \mu \mathrm{m}$ in the Ti-55521 alloy, respectively which is approximately constant in comparison with assintered condition. The area fraction of grain boundary $\alpha$ phase was $0.7 \%$ in the Ti-55511 alloy and $0.8 \%$ in the Ti- 
55521 alloy. The width of the grain boundary $\alpha$ phase reduced to $0.99 \pm 0.35 \mu \mathrm{m}$ in the Ti-55511 and $1.01 \pm 0.28 \mu \mathrm{m}$ in the

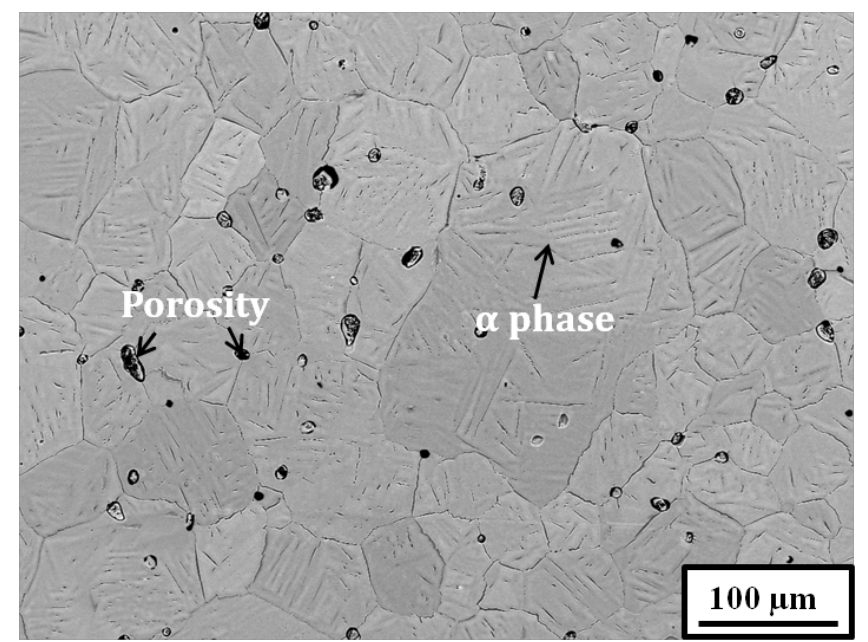

(a)

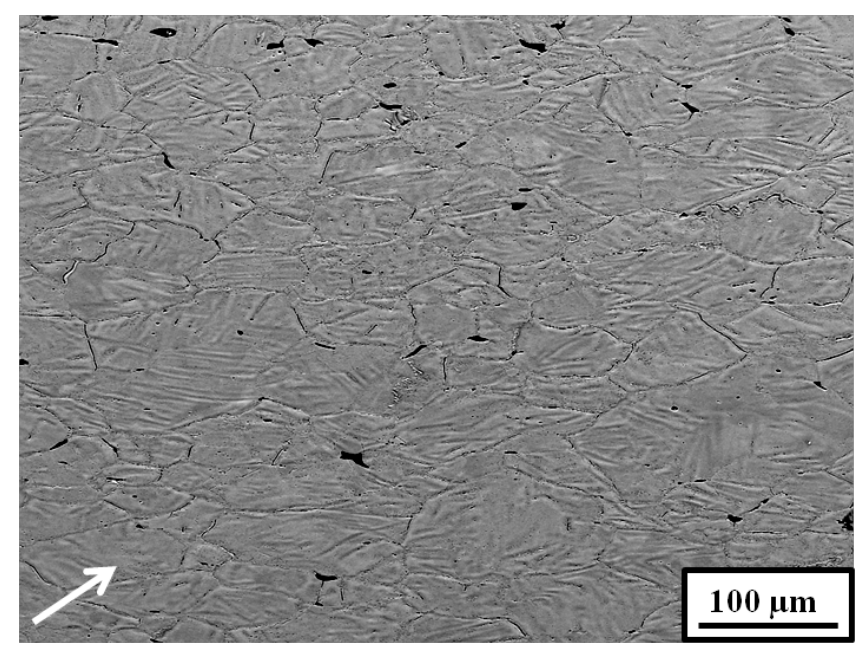

(c)

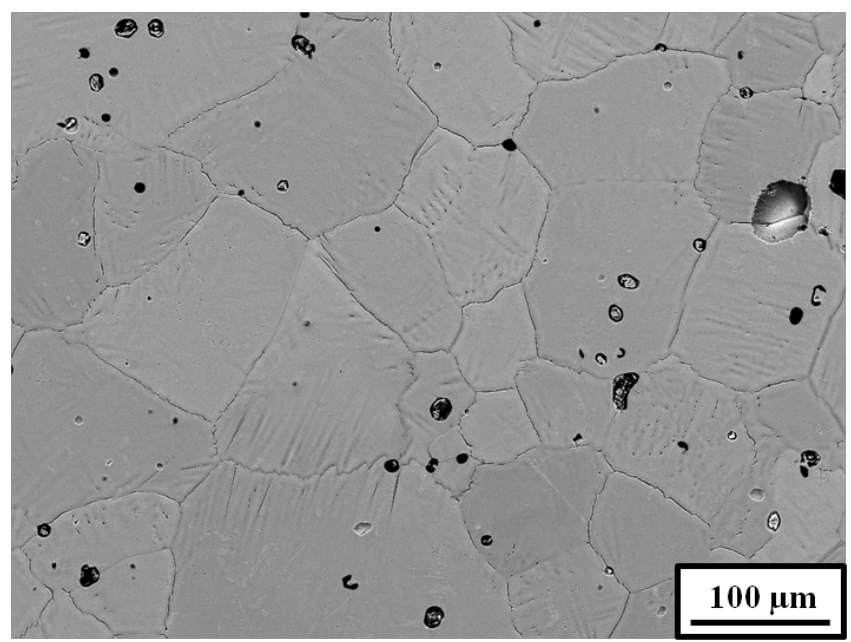

(b)

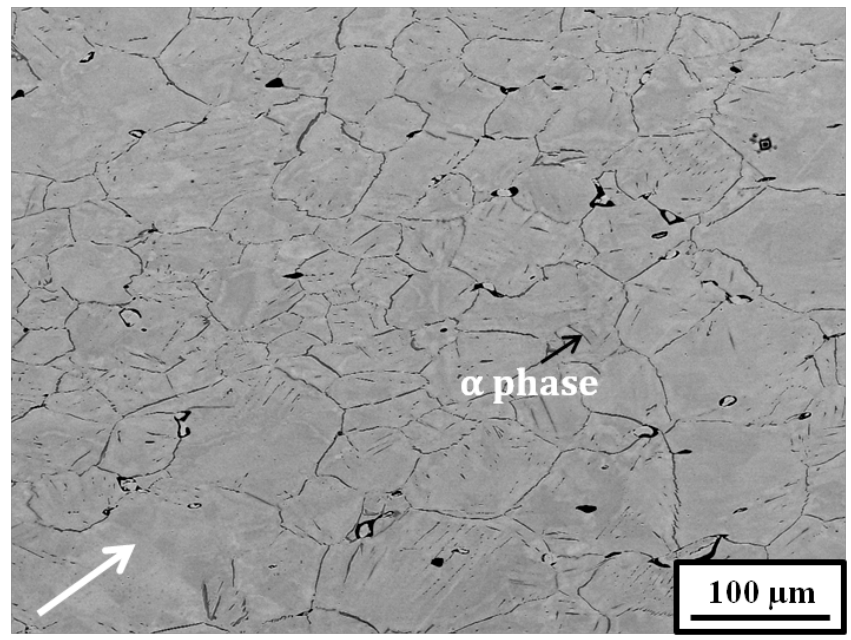

(d)

Figure 3: Back-scattered electron images of $(a, c)$ Ti-55511 and (b,d) Ti-55521 alloys after (a,b) step I and (c,d) step II of the thermo-mechanical processing. White arrow in (c,d) denotes the deformation direction.

Ti-55521 alloys compared to the as-sintered condition (Figure 5). In addition, the area fraction of the $\alpha$ phase was $0.5 \%$ for both alloys, respectively (Figures 3 (a) and 3 (b)).

Figures 3(c) and 3(d) are the representative microstructures after step II (25\% deformation at $1173 \mathrm{~K}\left(900^{\circ} \mathrm{C}\right)+$ step I) of both alloys. The direction of deformation is marked by a white arrow in Figures 3(c) and 3(d). Deformation in the $\beta$ phase field (Step II) significantly reduced the amount of porosity in both alloys in comparison with step I. The measured porosity was $0.3 \%$ and $0.6 \%$ for the Ti-55511 and Ti-55521 alloys, respectively. A significant reduction in the average $\beta$ grain size $(56 \pm 18 \mu \mathrm{m}$ for the Ti-55511 alloy and $54 \pm 15 \mu \mathrm{m}$ for the 
Ti-55521 alloy) was also observed after step II. The area fraction of grain boundary $\alpha$ phase increased to $1.5 \%$ in the Ti55511 alloy and $2.3 \%$ in the Ti-55521 alloy as a result of $\beta$ grains subdivision due to the deformation at $1173 \mathrm{~K}$ $\left(900^{\circ} \mathrm{C}\right)$. The area fraction of $\alpha$ phase also increased to $1.3 \%$ in the Ti-55511 alloy and $1.4 \%$ in Ti-55521 alloys, respectively. An obvious reduction in the width of the grain boundary $\alpha$ phase and $\alpha$ phase is clearly visible in the microstructures when compared to the as-sintered condition and after step I. The reduced width of the grain boundary $\alpha$ phase was $0.65 \pm 0.15 \mu \mathrm{m}$ and $0.92 \pm 0.31 \mu \mathrm{m}$ in both alloys, respectively after step II (Figure 5). Although, continuous grain boundary $\alpha$ phase was still predominant in the microstructures of both alloys, localised regions containing fragmented grain boundary $\alpha$ phase was also seen.

\subsubsection{Microstructure after soaking and deformation at $\alpha+\beta$ phase field:}

The BSE microstructures of the studied alloys after step III (Figures $4 a$ and $4 b$ ), step IIIa (Figures 4c and 4d), and step IV (Figures 4 e and 4f) are shown in Figure 4. The microstructures after soaking in $\alpha+\beta$ phase field show the transformation of $\beta$ phase to the $\alpha$ phase along with a broadening of the width of the $\alpha$ constituents. The microstructures of the alloys were refined during soaking at $1023 \mathrm{~K}\left(750^{\circ} \mathrm{C}\right)$ for 1800 s.

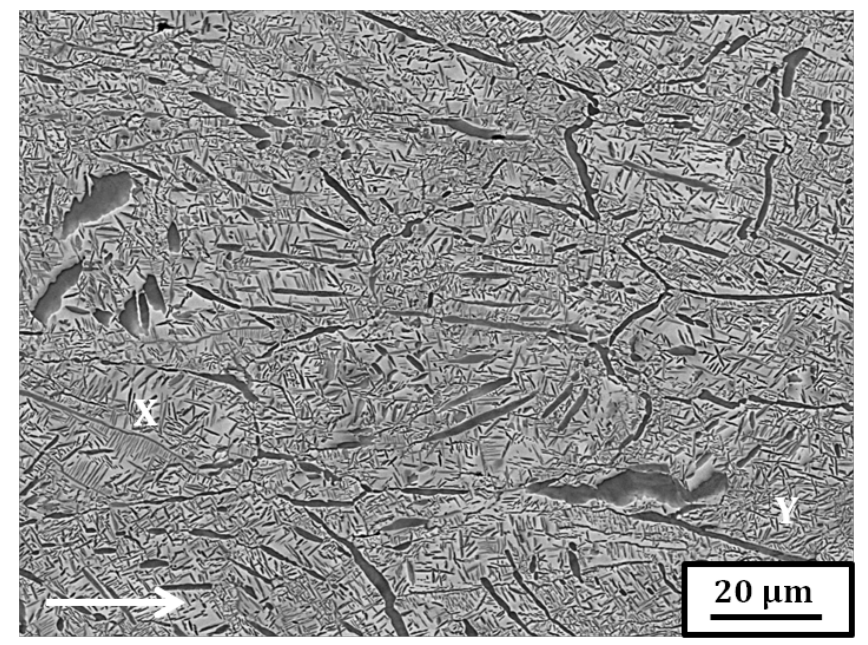

(a)

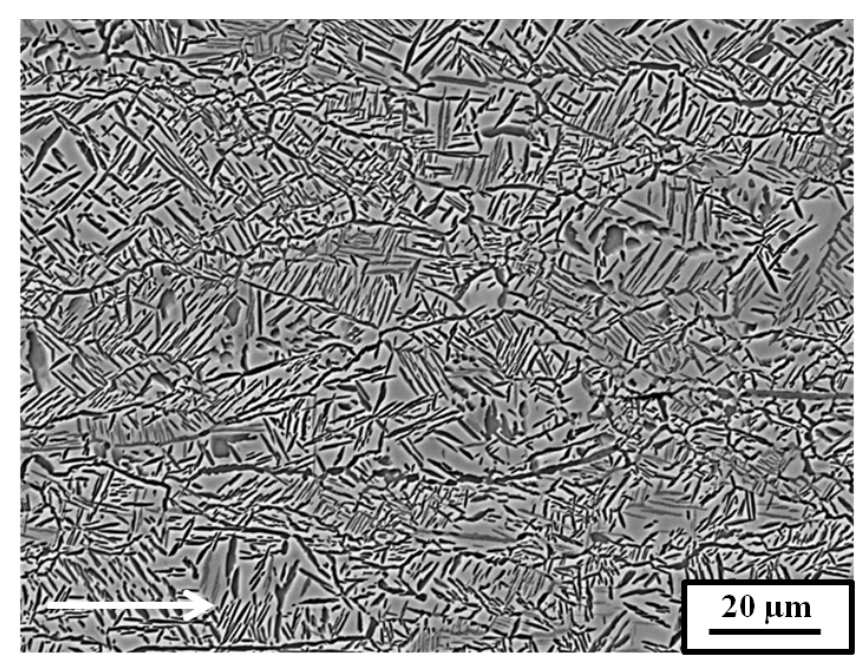

(c)

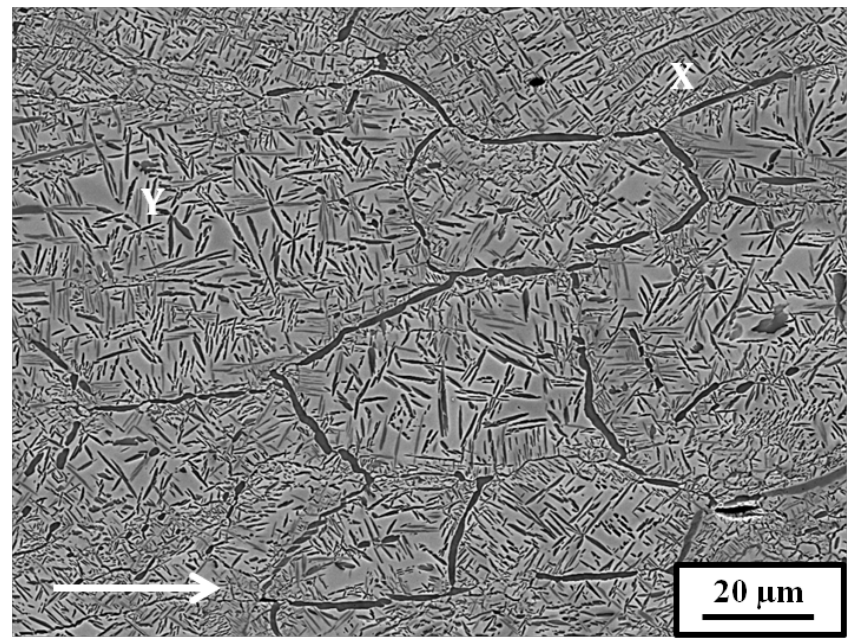

(b)

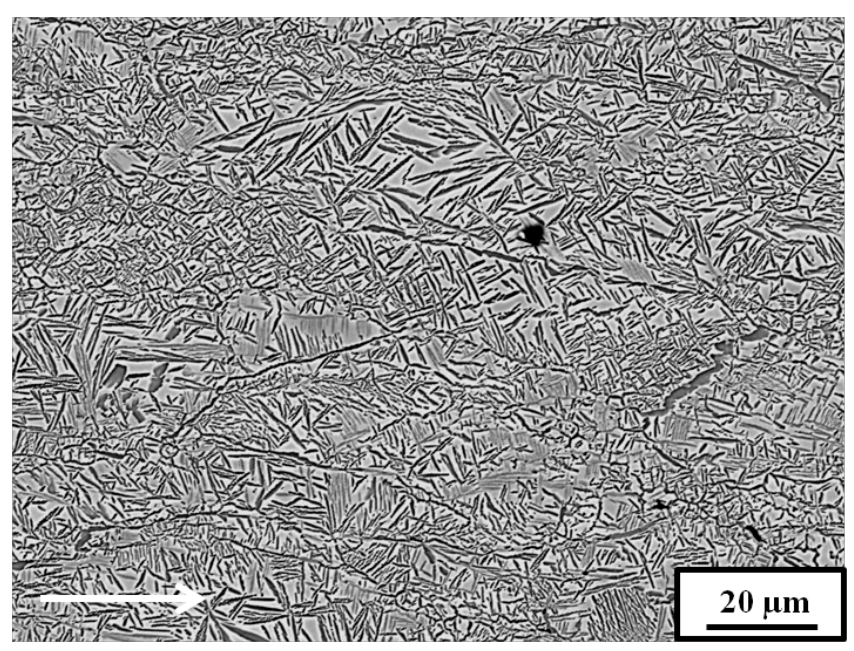

(d) 


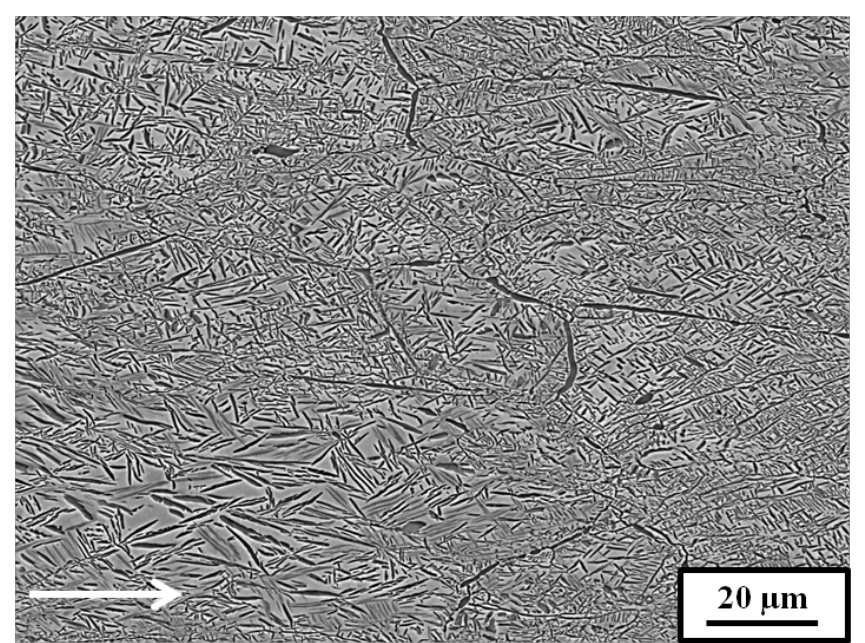

(e)

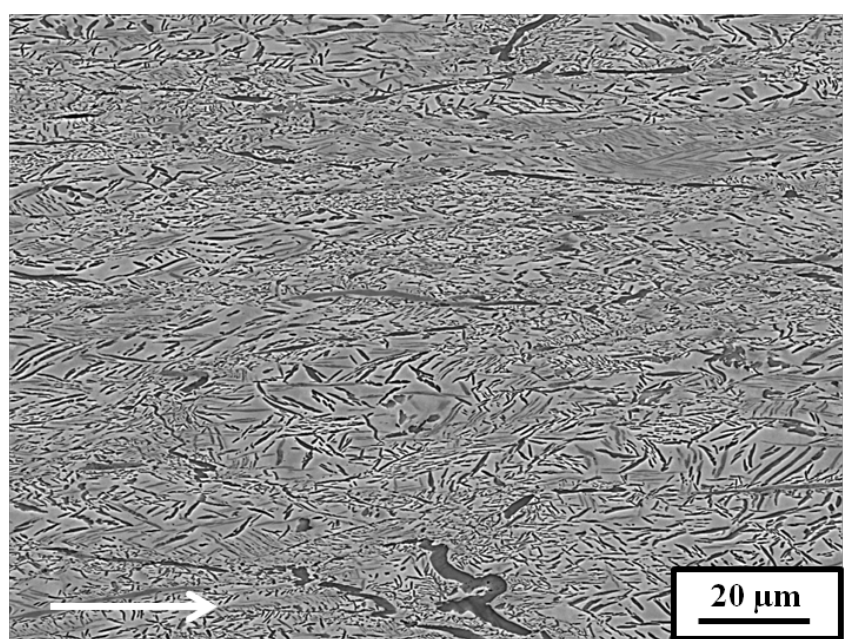

(f)

Figure 4: Back-scattered electron images of $(a, c, e)$ Ti-55511 and (b,d,f) Ti-55521 alloys after $(a, b)$ step III, (c,d) step III(a) and (e,f) step IV of the thermo-mechanical processing. X in Figures $(a, b)$ indicates the colony and $Y$ in Figures $(a, b)$ indicates the basket-weave morphologies. White arrows indicate the deformation direction.

Figures 4a and 4b correspond to the microstructures of the Ti-55511 and Ti-55521 alloys, respectively after step III of TMP. Step III processing resulted in a reduction of the porosity to $0.1 \%$ for both alloys. The $\beta$ grain size was $58 \pm 16 \mu \mathrm{m}$ in the Ti-55511 alloy and 55 $\pm 18 \mu \mathrm{m}$ in the Ti-55521 alloy which remained approximately constant in 


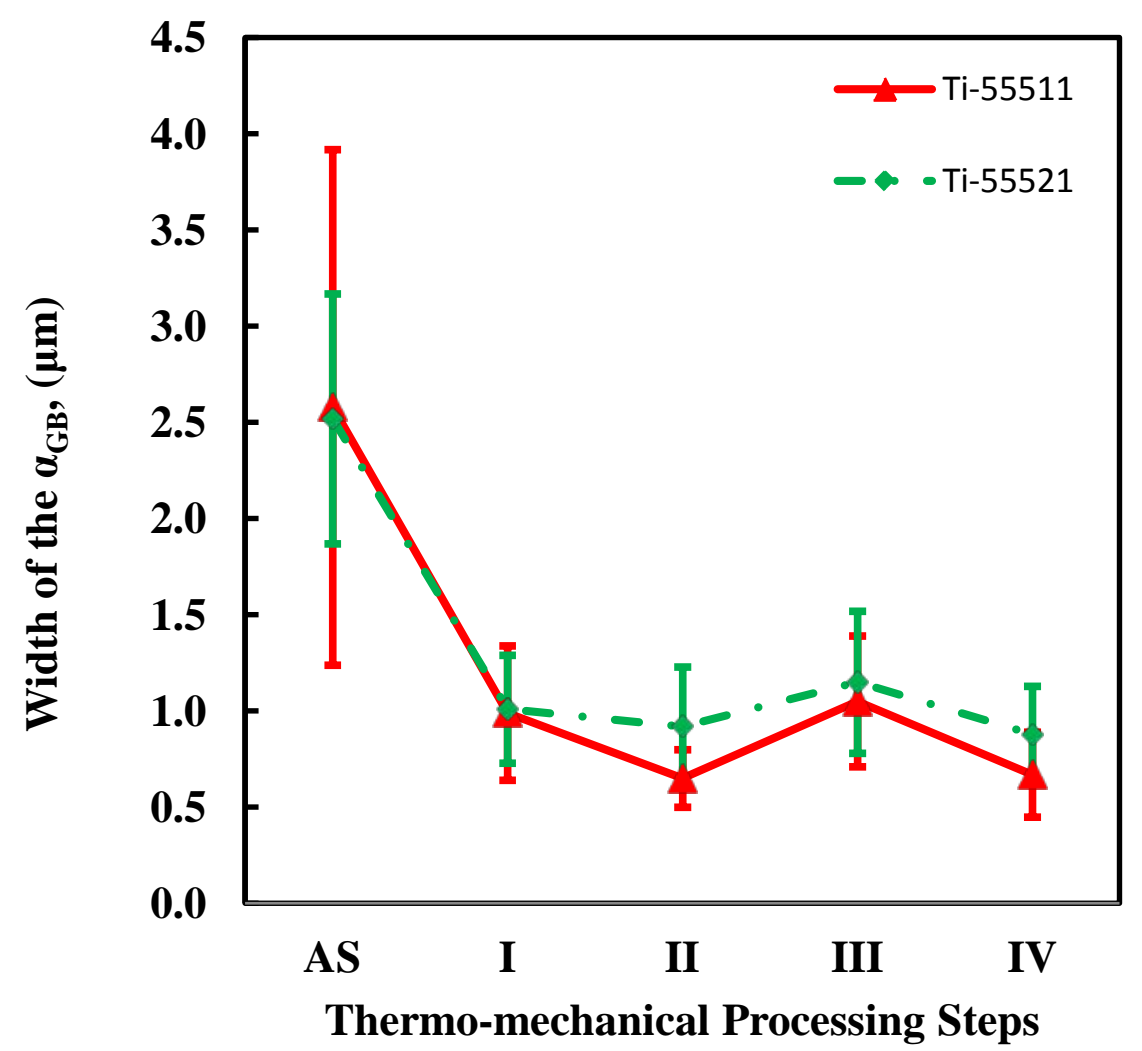

Figure 5: Variation of the width of the grain boundary $\alpha\left(\alpha_{\mathrm{GB}}\right)$ phase with the thermo-mechanical processing steps. Step III(a) is not plotted in the above Figure due to its different parameters. The width of the grain boundary $\alpha$ after step III(a) is presented in the Tables 2 and 3 for both alloys.

comparison with step II. The area fraction of the grain boundary $\alpha$ increased slightly to $3.6 \%$ in the Ti-55511 alloy and $3.7 \%$ in the Ti-55521 alloy due to the broadening of width of the grain boundary $\alpha$ phase. The width of the grain boundary $\alpha$ phase increased to $1.05 \pm 0.34 \mu \mathrm{m}$ and $1.15 \pm 0.37 \mu \mathrm{m}$ in the both alloys, respectively after step III (Figure 5). On the other hand, the area fraction of the $\alpha$ phase increased most noticeably to $34.1 \%$ in the Ti-55511 alloy and 29.6\% in the Ti-55521 alloy. The $\alpha$ phase had both, colony-type (marked with the letter "X" in Figures 4 (a) and (b)) as well as basket weave type (marked with the letter "Y" in Figures 4 (a) and (b)) morphologies in both alloys.

The microstructures shown in Figures 4(c) and 4(d) are obtained after step III(a) processing for both alloys respectively. The area fraction of porosity was $\sim 0.1 \%$ in both alloys and remained constant in comparison with step III. The $\beta$ grains were elongated along the direction of deformation as a result of higher deformation $(40 \%)$ at $1173 \mathrm{~K}\left(900^{\circ} \mathrm{C}\right)$. The area fraction of grain boundary $\alpha$ phase was 3.2\% in the Ti-55511 alloy and 3.4\% in the Ti-55521 alloy. The width of the grain boundary $\alpha$ phase was $0.76 \pm 0.26 \mu \mathrm{m}$ and $0.87 \pm 0.23 \mu \mathrm{m}$ in the Ti-55511 and Ti-555521 alloys, respectively which is lower than the step III due to the narrowing of the width of the grain boundary $\alpha$ phase (Tables 2 and 3). The area fraction of the $\alpha$ phase was $34.7 \%$ in the Ti-55511 alloy and 31.9\% in the Ti-55521 alloy after step III(a). A slight increment in the area fraction of $\alpha$ phase was observed in the Tables 2 and 3 after step III(a) in comparison with after step III. 
Figures 4(e) and 4(f) show the microstructures of both alloys after step IV which consisted of an additional $40 \%$ deformation at $1023 \mathrm{~K}\left(750^{\circ} \mathrm{C}\right)$ in the $\beta$ phase field after step III. The area fraction of the porosity decreased slightly to $0.07 \%$ in the Ti-55511 alloy and $0.03 \%$ in the Ti-55521 alloy, respectively as a result of deformation at $1023 \mathrm{~K}$ $\left(750^{\circ} \mathrm{C}\right)$. The area fraction of the grain boundary $\alpha$ phase reduced to $2.1 \%$ in the Ti-55511 alloy and $3.1 \%$ in the Ti55521 alloy through the fragmentation along with a narrowing of their width. The measured width of the grain boundary $\alpha$ was $0.67 \pm 0.22 \mu \mathrm{m}$ in the Ti-55511 alloy and $0.88 \pm 0.25 \mu \mathrm{m}$ in the Ti-55521 alloy. While the narrowing of the grain boundary $\alpha$ phase was predominant in the Ti-55511 alloy, the fragmentation of the same phase was more in the Ti-55521 alloy. The area fraction of the $\alpha$ phase increased slightly to $35.9 \%$ in the Ti-55511 alloy and $32.3 \%$ in the Ti-55521 alloy.

\subsection{Distribution of alloying elements between the phases:}

Figures 6 and 7 show the x-ray elemental maps of the different alloying elements for the Ti-55511 and Ti-55521 alloys, respectively, after step IV processing. The alloying elements are found to be distributed rather uniformly throughout the $\beta$ matrix phase. The histograms in Figures 8 to 10 indicate the compositional variation in the alloying elements in the grain boundary $\alpha$ (Figure 8), $\alpha$ phase (Figure 9) and $\beta$ phase (Figure 10) after each TMP step for the Ti-55511 alloy (Figures 8a-10a) and for the Ti-55521 alloy (Figures 8b-10b) respectively. The diffusion rates of the alloying elements in $\alpha$ - and $\beta$-Ti at $1023 \mathrm{~K}\left(750^{\circ} \mathrm{C}\right)$ are shown in Table 4 obtained from [20-23]. From the Table 4, it is clear that Fe is the fastest diffusive element and Mo has the slowest diffusivity in $\beta$-phase. The diffusion rate of Cr is slower than that of Fe but faster than of other alloying elements (Al, Mo, and V). V and Al have approximately similar diffusion rates, which are intermediate between $\mathrm{Cr}$ and Mo ones. The solubility of the alloying elements in both $\alpha$-Ti and $\beta$-Ti at $1023 \mathrm{~K}$ $\left(750^{\circ} \mathrm{C}\right)$ processing temperature is shown in Table 5 obtained from [24]. The descending solubility order of the alloying elements is $\mathrm{Mo}>\mathrm{V}>\mathrm{Cr}>\mathrm{Fe}>\mathrm{Al}$ in $\beta$-Ti and $\mathrm{Al}>\mathrm{Mo}>\mathrm{Cr}>\mathrm{V}>\mathrm{Fe}$ in $\alpha-\mathrm{Ti}$.

\subsubsection{Distribution in grain boundary $\alpha$ phase:}

The changes in the amount of alloying elements in the grain boundary $\alpha$ phase after each TMP step is shown in Figure 8(a) for the Ti-55511 alloy and in Figure 8(b) for the Ti-55521 alloy, respectively. The extent of $\alpha$-stabilising alloying element (Al) remained approximately constant throughout the TMP in the Ti-55511 alloy. In contrast, the amount of Al increased slightly after step III and thereafter remained
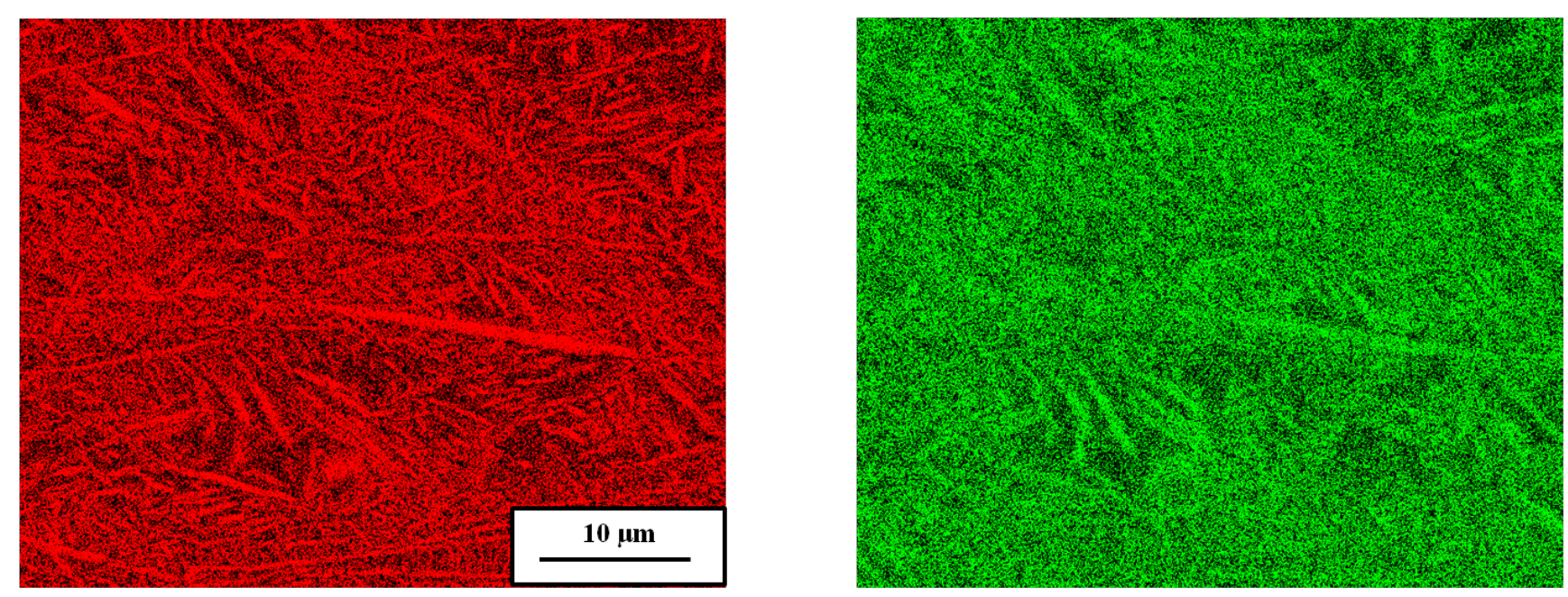
(a)

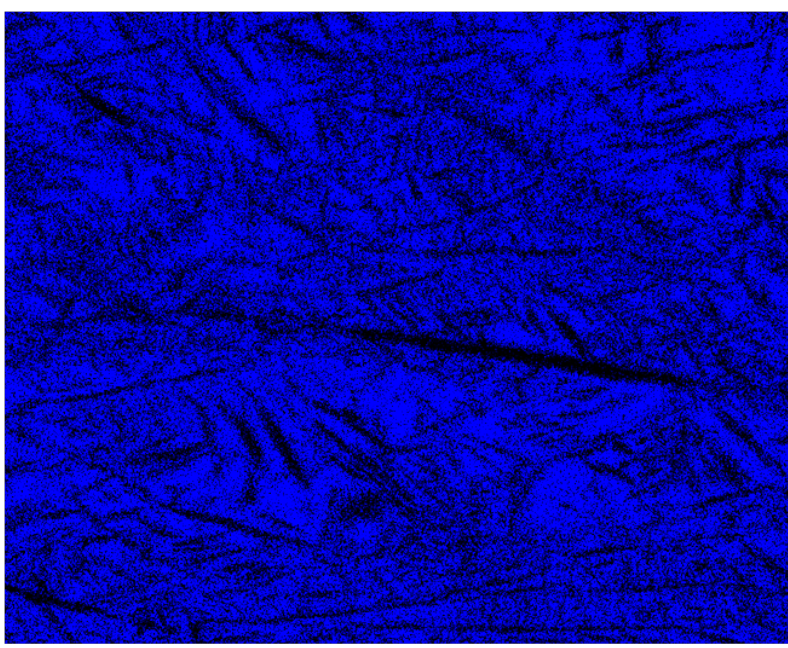

(c)

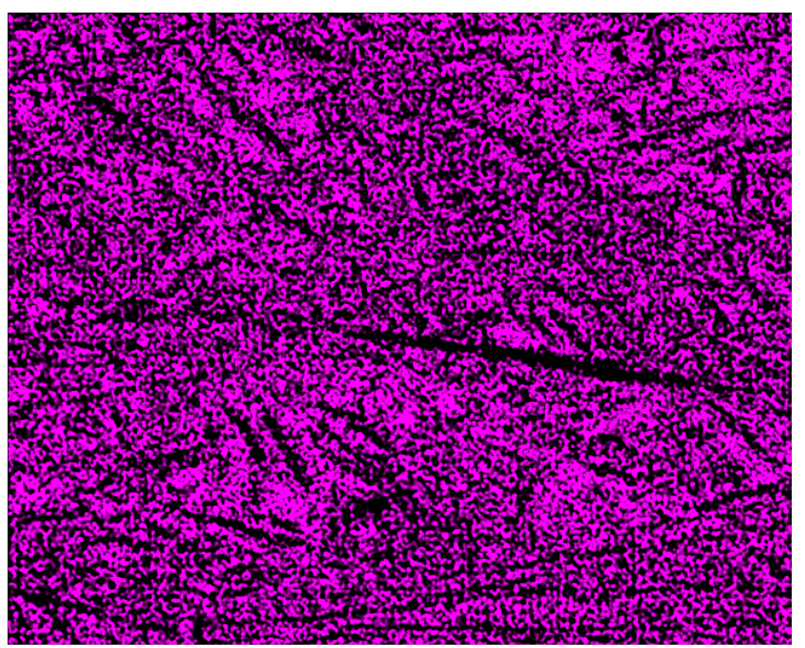

(e) (b)

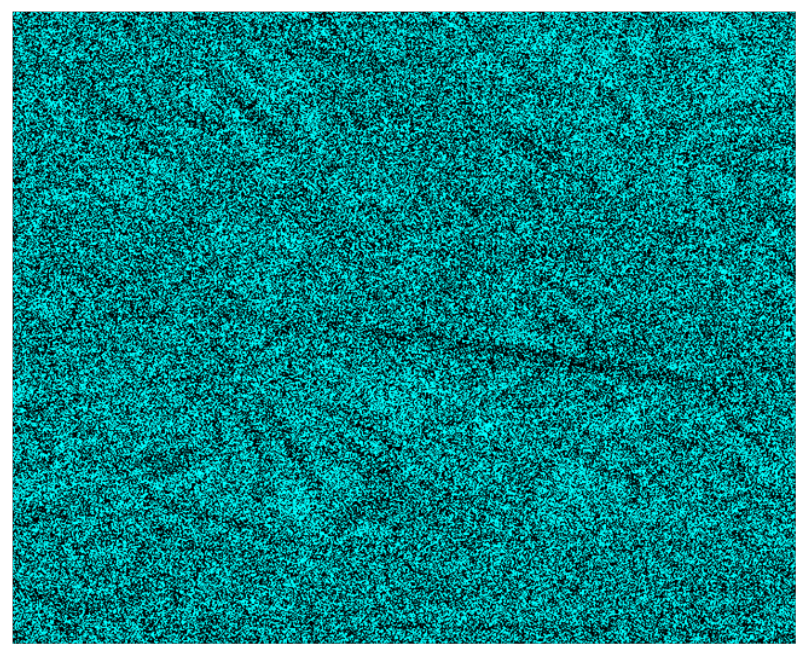

(d)

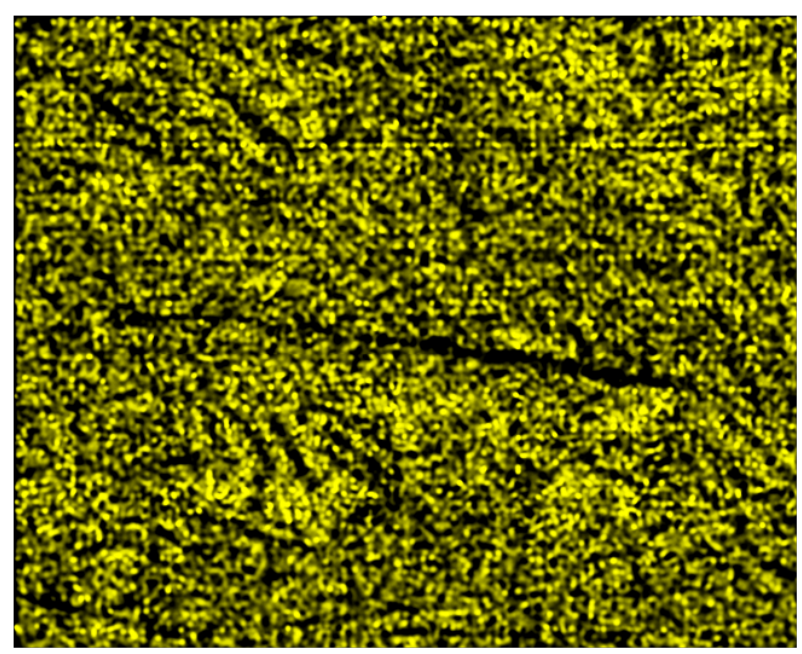

(f)

Figure 6: X-ray elemental maps of Ti-55511 alloy after step IV (a) Ti, (b) Al, (c) Mo, (d) V, (e) Cr and (f) Fe.

constant in the Ti-55521 alloy. The amount of $\beta$ stabilising element, Mo, reduced slightly after step III in the Ti-55511 alloy. In contrast, the Mo content remained approximately constant throughout the processing steps in the case of the Ti-55521 alloy. A significant decrease in the amount of V, Cr and Fe was observed in both alloys after step III. The 


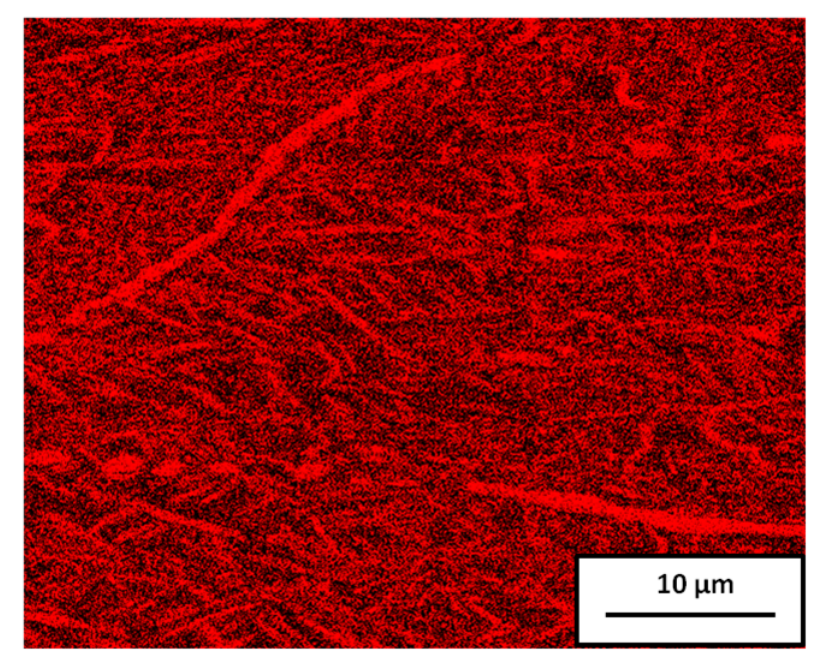

(a)

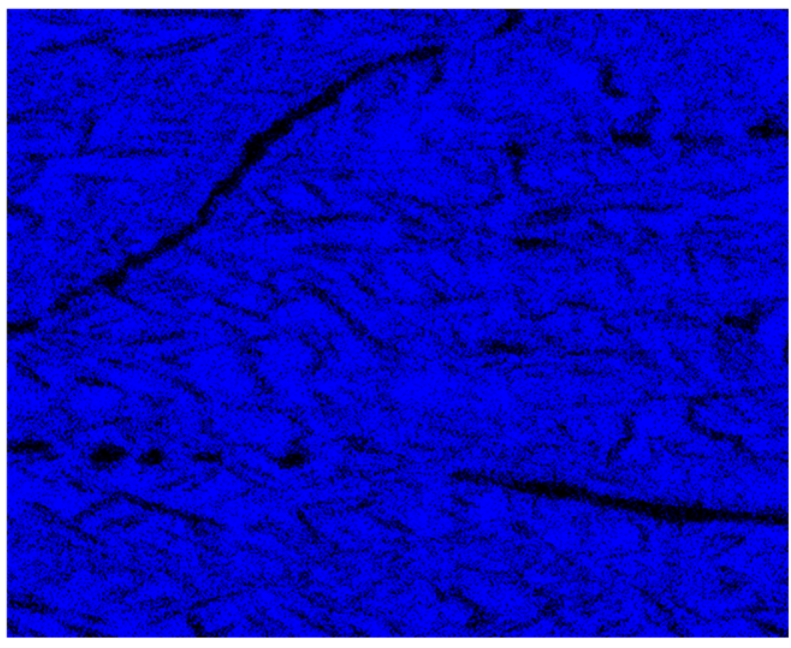

(c)

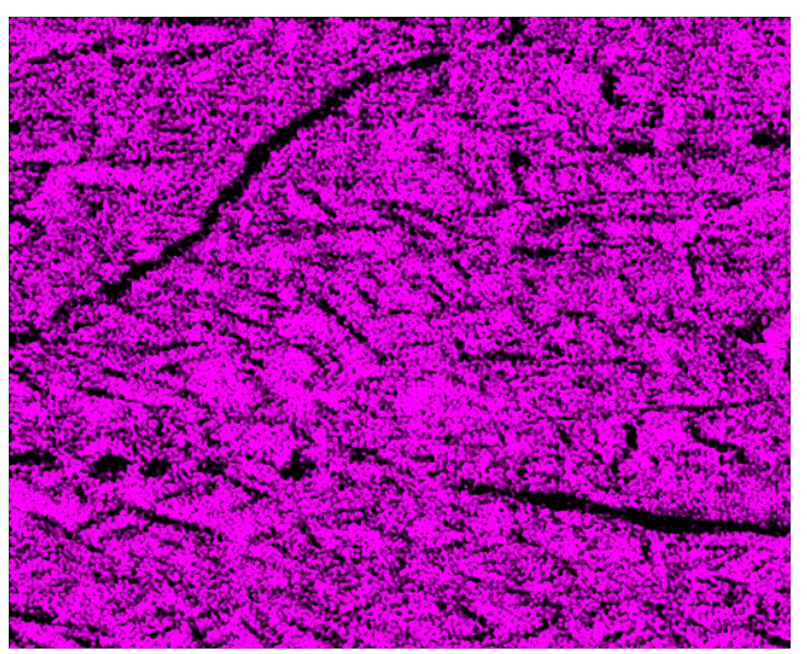

(e)

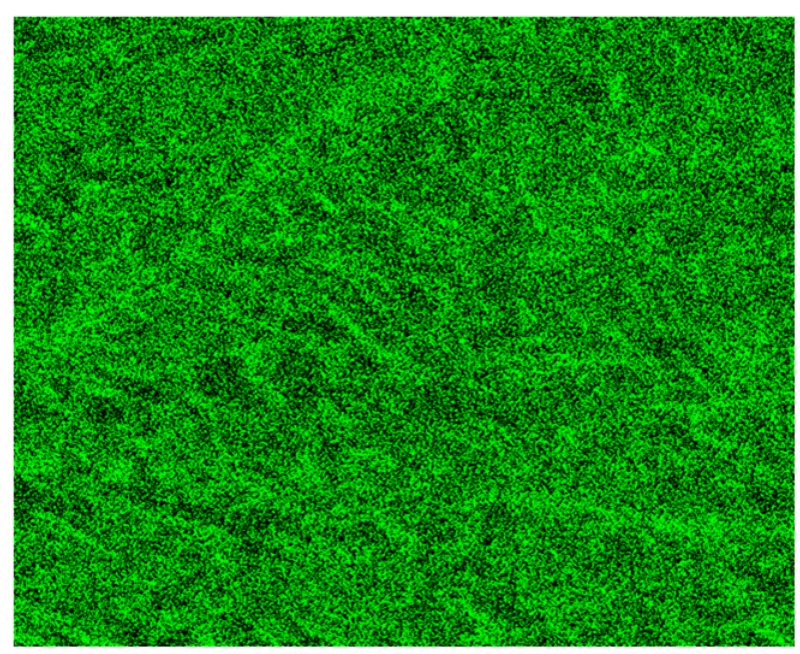

(b)

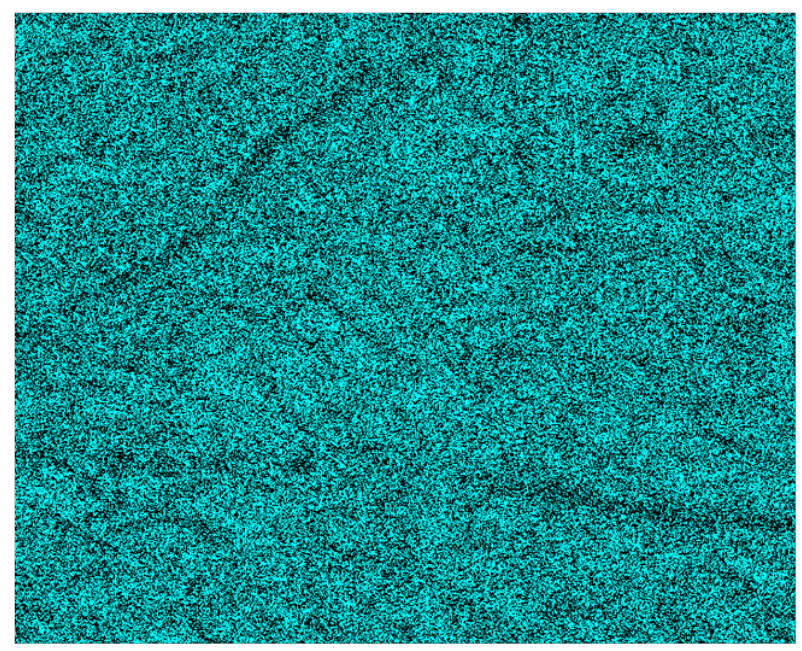

(d)

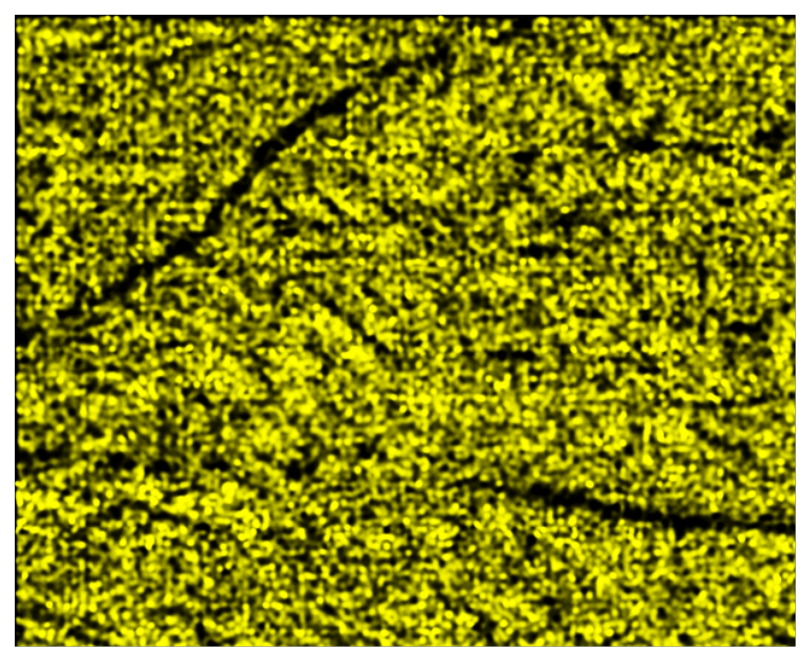

(f) 
Figure 7: X-ray elemental maps of Ti-55521 alloy after step IV (a) Ti, (b) Al, (c) Mo, (d) V, (e) Cr and (f) Fe.

amount of $\alpha$ stabilising alloying element (Al) and $\beta$ stabilising alloying elements (Mo, V, Cr and Fe) was approximately the same after steps III and III(a) in both alloys. In addition, there was no deviation in the concentration of the alloying elements after steps III and step IV in both alloys.

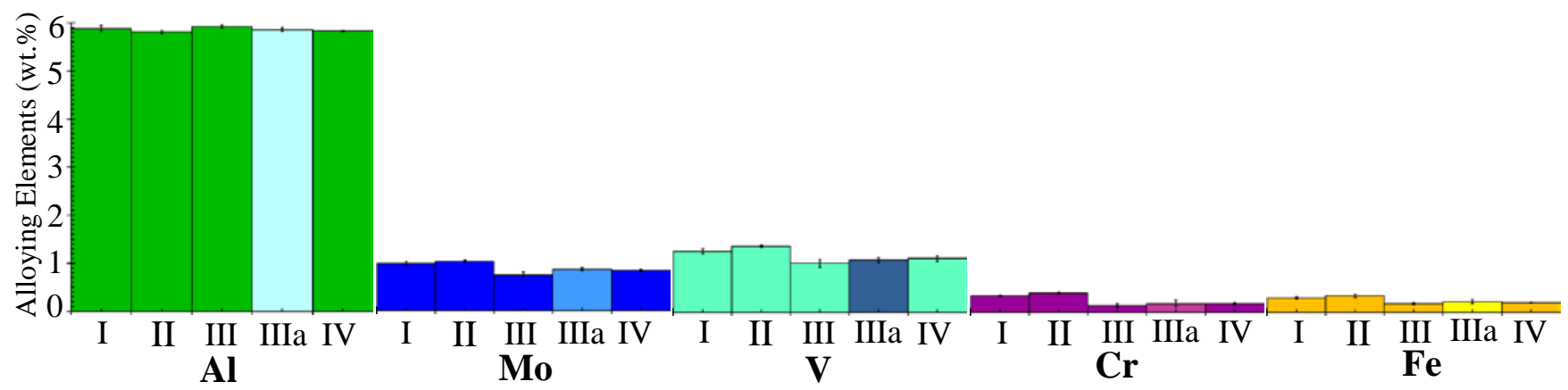

(a)

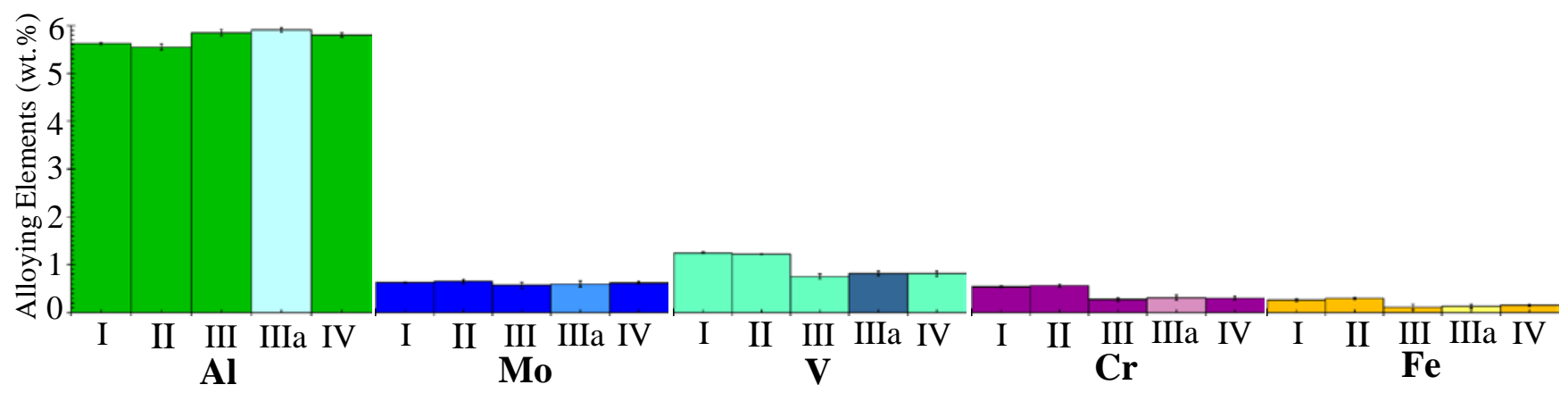

(b)

Figure 8: Variation in grain boundary $\alpha$ phase $\left(\alpha_{\mathrm{GB}}\right)$ alloy composition with thermo-mechanical processing through Steps I to IV in: (a) Ti-55511 and (b) Ti-55521 alloys.

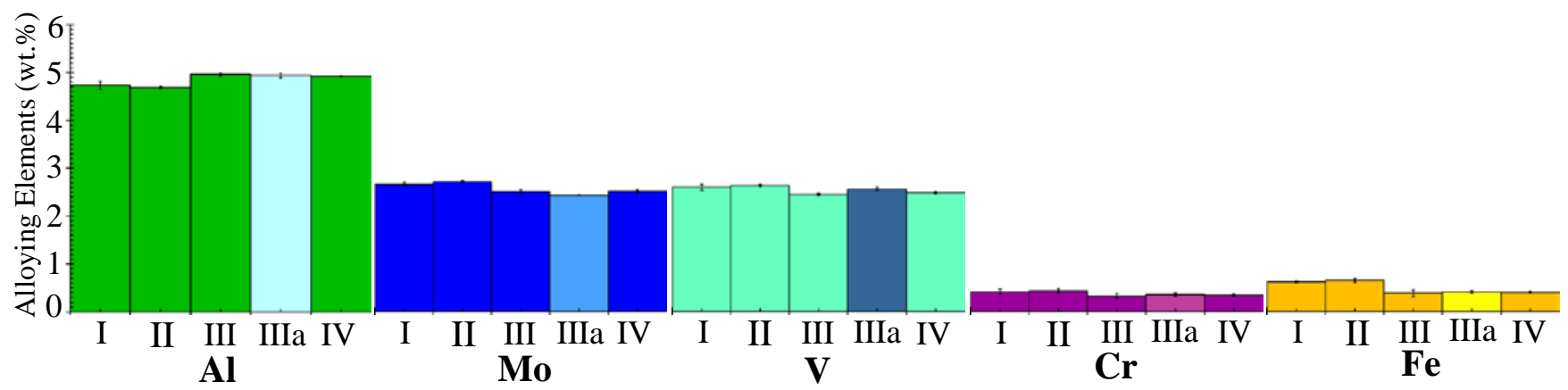


(a)

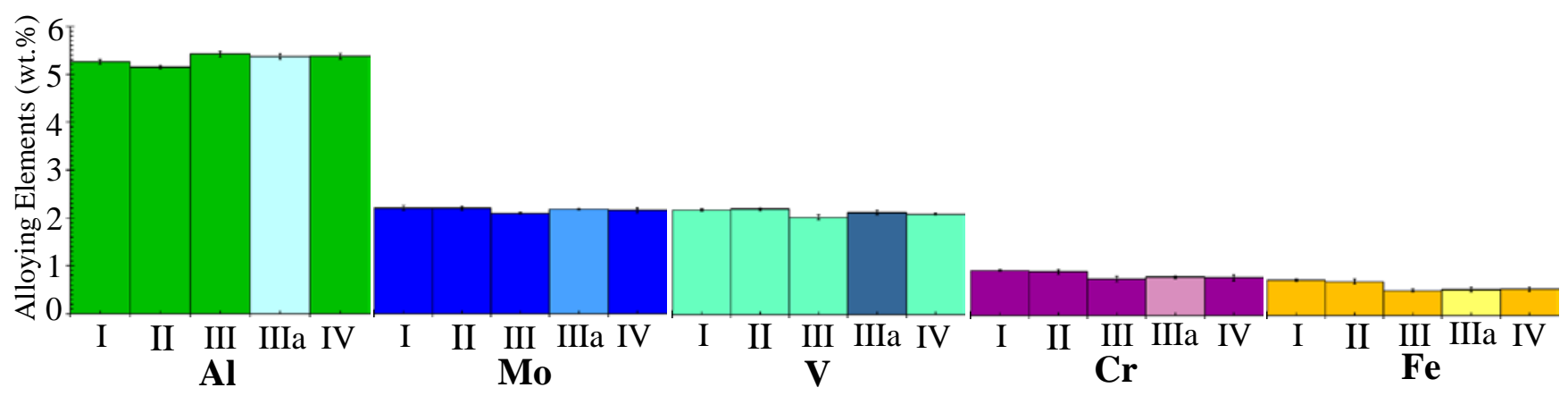

(b)

Figure 9: Variation in the $\alpha$ phase $(\alpha)$ alloy composition with thermo-mechanical processing through Steps I to IV in: (a) Ti-55511 and (b) Ti-55521 alloys.

\subsubsection{Distribution in $\alpha$ phase:}

The variation of the concentration of the alloying elements in the $\alpha$ phase is shown in Figures 9 (a and b) for both alloys. It could be seen from the histogram of all alloying elements that, there was approximately no variation in the alloying elements content in $\alpha$ phase after steps $\mathrm{I}$ and $\mathrm{II}$ in both alloys. The amount of $\mathrm{Al}$ content in $\alpha$ phase increased slightly after step III for both alloys. Thereafter, it remained approximately constant after step IV. Between steps III and III(a), there was no change in Al content for both alloys. The concentration of Mo and V was not changed throughout the thermo-mechanical processing except slight reduction occurred after step III in both alloys. In case of both alloys, the amount of $\mathrm{Cr}$ and Fe decreased after step III and remained then constant during further processing. There was approximately no variation in the concentration of the $\beta$-stabilising alloying elements after steps III and III(a) in both alloys.

\subsubsection{Distribution in beta ( $\beta)$ phase:}

Figures $10(a$ and $b$ ) indicate the variation in $\beta$ phase alloy composition with TMP through step I to step IV in the Ti55511 and Ti-55521 alloys, respectively. From the histogram for the $\alpha$ stabiliser, there was approximately no variation in $\mathrm{Al}$ content between step I and step II for both alloys. However, the amount of Al content reduced significantly after step III and remained thereafter constant after step IV in both alloys. Also, there was no variation in the $\mathrm{Al}$ concentration after steps III and III(a) for both alloys. Similarly, the main variation in the concentration of 


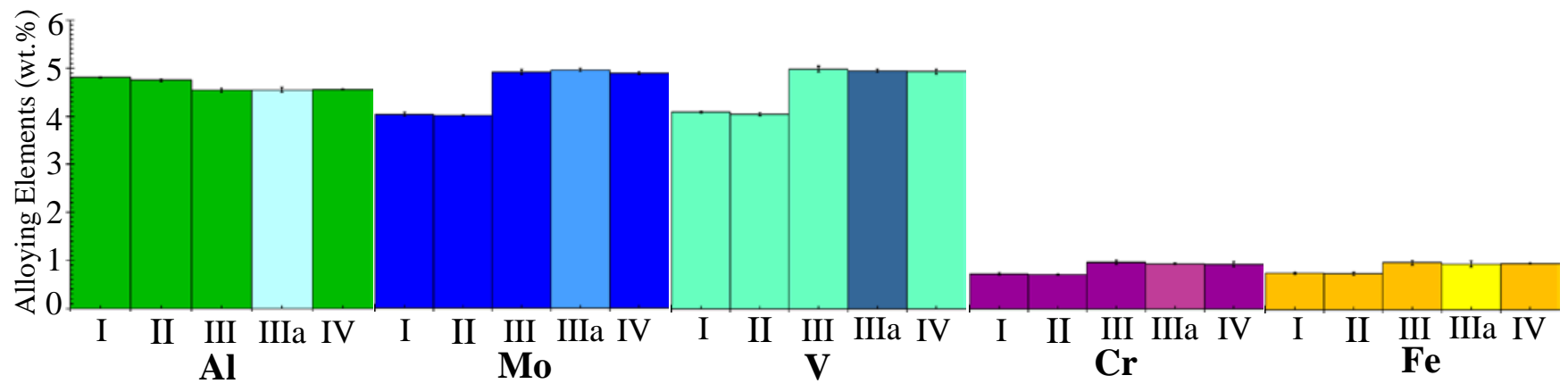

(a)

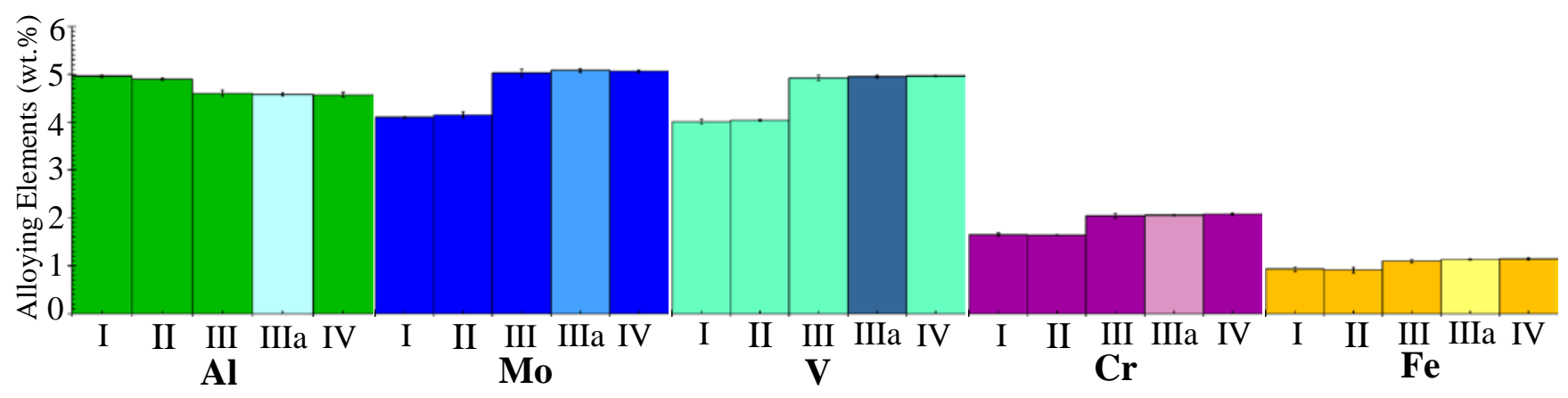

(b)

Figure 10: Variation in $\beta$ phase $(\beta)$ alloy composition with thermo-mechanical processing through Steps I to IV in: (a) Ti-55511 and (b) Ti-55521 alloys.

$\beta$ stabilisers (Mo, V, Cr and Fe) took place after step III. However, as expected, the distribution trend for the $\boldsymbol{\beta}$ stabilisers was the opposite one for the Al, i.e., their amount increased after step III and remained approximately constant thereafter. Between step III and step III(a), no variation in the concentration of $\beta$ stabilisers was also observed in $\beta$ phase for both alloys.

\section{DISCUSSION:}

\subsection{Microstructure:}

In the present study, the microstructure evolution during thermo-mechanical processing is investigated with respect to the area fraction of the porosity, the $\beta$ grain size and the constituent phases. Through the thermo-mechanical processing, the microstructures of the two alloys were refined in terms of $\beta$ grain size as well as $\alpha$ phases (grain boundary $\alpha$ and $\alpha$ phase). The significant amount of porosity inherited from sintering was closed through applying deformation at $1173 \mathrm{~K}\left(\mathbf{9 0 0}^{\circ} \mathrm{C}\right)$ for both alloys. Porosity was also reduced during step III by healing pores through the activated diffusion at high density of crystal defects formed during deformation of step II [5]. The average $\boldsymbol{\beta}$ grain size was slightly coarser in the Ti-55511 alloy after steps I to III in comparison with the Ti-55521 alloy. Zhao et al. [14] reported the effect of $\mathrm{Cr}$ on reducing the $\beta$ grain coarsening in Ti-25V-15Cr-0.2Si alloy compared to Ti-25V-10Cr-0.2Si 
alloy. No $\beta$ grain growth was observed after step III because residual pores as well as the $\alpha$ phase presented at this stage prevented it. $\beta$ grain size corresponding to the Steps III(a) to IV were not recorded in Tables 2 and 3 because the $\beta$ grains were elongated along the deformation direction after steps III(a) and IV. The average width of the grain boundary $\alpha$ decreased after step II for both alloys due to the deformation at high temperature in the $\beta$ phase field (Figure 5). The width of the grain boundary $\alpha$ increased after step III due to the soaking at $1023 \mathrm{~K}\left(750^{\circ} \mathrm{C}\right)$ and thereafter decreased with further processing. During step III, the area fraction of the grain boundary $\alpha$ increased $(2.1 \%$ for the Ti55511 and $1.4 \%$ for the Ti-55521 alloys) slightly due to the coarsening of the grain boundary $\alpha$, as the average width increased from $0.65 \pm 0.15 \mu \mathrm{m}$ to $1.05 \pm 0.34 \mu \mathrm{m}$ in the Ti-55511 alloy and from $0.92 \pm 0.31 \mu \mathrm{m}$ to $1.15 \pm 0.37 \mu \mathrm{m}$ in the Ti55521 alloy (Figure 5). Interestingly, the area fraction of the grain boundary $\alpha$ decreased after step IV. It may have two reasons: (i) through the reduction of the width of the grain boundary $\alpha$ and (ii) some fragmented parts of the grain boundary $\alpha$ were considered as $\alpha$ phase due to their size and shape. There was still a very small amount of the $\alpha$ phase ( $0.50 \%$ in both alloys) present in the microstructure after step I because 120s annealing time in the $\boldsymbol{\beta}$ phase field (1223 K) was insufficient to dissolve the $\alpha$ phase completely which carried over from the sintering stage. However, $120 \mathrm{~s}$ annealing time was used to minimise the $\beta$ grain growth. Deformation during steps II and IV increased the area fraction of the $\alpha$ phase; there may have two reasons: (i) increase in dislocation density which serve as nucleation sites for $\alpha$ phase and (ii) the fragmented grain boundary $\alpha$ was considered as $\alpha$ phase due to their size and shape. The soaking at $1023 \mathrm{~K}\left(750^{\circ} \mathrm{C}\right)$ in the $\alpha+\beta$ phase field for 1800 s resulted in $32.8 \% \alpha$ phase in the Ti-55511 alloy and $28.2 \%$ in the Ti55521 alloy through the progress of diffusion-controlled $\beta \rightarrow \alpha$ phase transformation. In comparison, the amount of $\alpha$ phase produced in the Ti-55521 alloy was less than in the Ti-55511 alloy during step III. It is due to the effect of the $1 \%$ additional $\mathrm{Cr}$ content in the Ti-55521 alloy on the $\beta$ phase transformation to $\alpha$ phase. As additional $1 \% \mathrm{Cr}$ increased the Mo equivalent of the alloy which ultimately lowers the $\beta$ transus temperature [12] of the Ti-55521 alloy compared to that for Ti-55511 alloy. So, the temperature difference between the $\beta$ transus temperature to soaking temperature $\left(750^{\circ} \mathrm{C}\right)$ in the $\alpha+\beta$ phase field is larger for the Ti-55511 alloy than for the Ti-55521 alloy. Thus, more $\alpha$ phase formed in Ti-55511 alloy than in Ti-55521 alloy. Previous studies [25, 26] of the Ti-10V-2Fe3Al and Ti-LCB alloys, have also found that larger amount of $\alpha$ phase formed when the temperature difference between the $\beta$ transus temperature and soaking temperature in the $\alpha+\beta$ phase field was also larger. Higher amount of $\alpha$ phase (34.7\% for the Ti-55511 alloy and 31.9\% for the Ti-55521 alloy) was obtained after step III(a) than after step III. Higher amount of deformation (40\% vs $25 \%$ ) in the $\beta$ phase field created more dislocations which serve as nucleation sites for the $\alpha$ phase during subsequent soaking at $1023 \mathrm{~K}\left(750^{\circ} \mathrm{C}\right)$. Thus, more $\alpha$ phase obtained after step III(a) than step III.

\subsection{Alloying elements distribution between the phases:}

Diffusivity of the alloying elements is calculated in binary system (Ti-X, where $\mathrm{X}=$ alloying elements). If more than one alloying element is added to the system, diffusivity of all alloying elements change [20, 27]. Yang et al. [27] mentioned that diffusivity of a fast diffusion element is decreased by adding less diffusive element and diffusivity of less diffusive element increase simultaneously. It was reported in [20] that the addition of 4.36 wt.\% of Al to Ti decreased the diffusivity of $\mathrm{Cr}$ from $2.839 \times 10^{-16} \mathrm{~m}^{2} / \mathrm{s}$ to $1.183 \times 10^{-16} \mathrm{~m}^{2} / \mathrm{s}(\sim 2.4$ times $)$ at $874 \mathrm{~K}\left(601^{\circ} \mathrm{C}\right)$ because Al has lower diffusivity than $\mathrm{Cr}$ in Ti. According to the diffusion rate of Fe and $\mathrm{Cr}$ in $\alpha$-Ti from Table 4, Fe should move at least 6.6 $\mu \mathrm{m}$ and $\mathrm{Cr}$ should move $1.71 \mu \mathrm{m}$ distances during 1800 s of soaking at $1023 \mathrm{~K}\left(750^{\circ} \mathrm{C}\right)$. These distances are much smaller than the width of grain boundary $\alpha$ after step III and it is clear that this time is not sufficient to remove the super 
saturation of $\mathrm{Fe}$ and $\mathrm{Cr}$ in grain boundary $\alpha$. Thus, $\beta$ stabilising alloying elements of the grain boundary $\alpha$ could not reach the equilibrium concentration after step III, due to insufficient time, indicated in Table 5. From Figures 8-10, it is clear that phase transformation from $\beta$ phase to $\alpha$ phase occurred during TMP step III through the diffusion of the alloying elements resulting in change in the composition and area fraction of the phases. With the formation of the $\alpha$ phase during step III, the area fraction of the $\alpha$ phase increases. The newly formed $\alpha$ which produced during step III may either increase or decrease the composition of the entire $\alpha$ phase (entire $\alpha$ phase $=$ the newly formed $\alpha$ which formed during step III + existing $\alpha$ which existed before step III). It depends on the composition and area fraction of the newly formed $\alpha$ and the existing $\alpha$ phase. If the newly formed $\alpha$ has higher concentration of alloying elements with larger area fraction than the existing $\alpha$ phase, the result is an increment in the alloy composition of the entire $\alpha$ phase. On the other hand, if the newly formed $\alpha$ is depleted in alloying elements and represents larger area fraction than the existing $\alpha$ phase, then this will decrease the alloy composition of the entire $\alpha$ phase. As a result of the described above process, as well as of diffusion of the $\beta$ stabilisers out of the $\alpha$ phase, the composition of the phases changed significantly after step III (Figures 8-10).

During step III and step III (a), the $\beta$ stabilisers diffused into the favoured $\beta$ phase and diffused out of the $\alpha$ phase. This phenomenon is also a factor to increase the $\boldsymbol{\beta}$ stabilisers content in the $\boldsymbol{\beta}$ phase. It is also noticeable that the concentration of the $\beta$ stabilisers is higher in the $\alpha$ phase than in the grain boundary $\alpha$ phase. As $\beta \rightarrow \alpha$ phase transformation is diffusion controlled [28], the first portions of newly formed $\alpha$ phase will have relatively high content of $\beta$ stabilising alloying elements, which inherited from the parent phase and had insufficient time to diffuse out. However, with time these $\beta$ stabilisers will diffuse out of the $\alpha$ phase in order for this phase to achieve equilibrium composition indicated in Table 5. However, time may not be sufficient to reach the equilibrium composition, thus the $\alpha$ phase remains saturated with $\beta$ stabilisers. On the other hand, the $\alpha$ phase formed at higher temperature (step I and step II) will have higher concentration of Al than $\alpha$ phase formed at lower temperature at 1023 $\mathrm{K}\left(750^{\circ} \mathrm{C}\right)$. This is due to the depletion of the $\mathrm{Al}$ in remaining $\beta$ phase as a result of initial $\alpha$ phase transformation. As there was no variation in the concentration of the alloying elements after Steps I and II, and steps III and IV, so it can be said that deformation in either $\beta$ or $\alpha+\beta$ phase field had no effect on the distribution of alloying elements between the phases for both alloys. In addition, higher deformation in the $\beta$ phase field did not affect on the distribution of the alloying elements.

\section{CONCLUSIONS:}

Microstructure and distribution of alloying elements of two near $\beta$ titanium alloys (Ti-55511 and Ti-55521) after thermo-mechanical processing showed that:

- As a result of TMP, porosity reduced to $0.07 \%$ for Ti-55511 alloy and $0.03 \%$ for Ti-55521 alloy. Most of the residual porosity has been closed during deformation at $1123 \mathrm{~K}\left(900^{\circ} \mathrm{C}\right)$ in the $\beta$ phase field.

- Due to the soaking at $1023 \mathrm{~K}\left(750^{\circ} \mathrm{C}\right)$ in the $\alpha+\beta$ phase region for $1800 \mathrm{~s}, 32.8 \% \alpha$ phase is obtained in Ti55511 alloy and $\mathbf{2 8 . 2} \%$ in Ti-55521 alloy. Fragmentation of continuous grain boundary $\alpha$ phase occurred through deformation in the $\alpha+\beta$ phase field. The morphology of the $\alpha$ phase and the distribution nature of the alloying elements between the phases was approximately the same in both alloys. 
- Elemental partitioning between the phases is observed in the alloys. Phase transformation from $\beta$ to $\alpha$ phase occurred through diffusion of the alloying elements. Higher concentration of $\beta$ stabilising alloying elements was in $\alpha$ phase than in the grain boundary $\alpha$ phase. In the case of both alloys, $\beta$ stabilising alloying elements could not reach their equilibrium content in $\alpha$ phase due to insufficient time. Higher deformation in the $\beta$ phase field as well as deformation in two-phase field had no effect on the variation of the alloying elements in the phases for the studied alloys.

- From the above discussion, it follows that alloying with additional $1 \%$ Cr content slightly reduces the amount of $\alpha$ phase formed, as well as $\boldsymbol{\beta}$ grain size, whereas the distribution of the alloying elements between the phases was not affected.

\section{ACKNOWLEDGEMENTS}

This work was supported by the Engineering Materials Institute strategic grant. The authors acknowledge technical support with Gleeble tests by Mr B. De Jong and Dr L. Chen, UOW and use of UOW Electron Microscopy Centre, in particular JEOL 7001F, which was purchased with ARC support (LE0882613). Mr Mansur Ahmed gratefully acknowledges the University of Wollongong Postgraduate Award (UPA) and useful discussions with Mr. M. Reid, UOW. 


\section{REFERENCES}

1. Moiseev VN (1998) Met Sci Heat Treat 40:482

2. Moiseev VN (2000) Met Sci Heat Treat vol. 42:81

3. Froes FH, Eylon D (1990) Int Mater Rev 35:162

4. Moxson V, Senkov ON, Froes FH (1998) Int J Powder Metall 34:45

5. Carman A, Zhang LC, Ivasishin OM, Savvakin DG, Matviychuk MV, Pereloma EV (2011) Mater Sci Eng A 528:1686

6. Savvakin DG, Carman A, Ivasishin OM, Matviychuk MV, Gazder AA, Pereloma EV (2012) Metall Mater Trans A 43:716

7. Ivasishin OM, Savvakin DG, Moxson VS, Bondareva KA, Froes FH (2002) Mater Technol Adv Perform Mater 17:20

8. Sauer C, Luetjering G (2001) J Mater Process Tech 117:311

9. Chesnutt J, Froes FH (1977) Metall Mater Trans A 8:1013

10. Clement N, Lenain A, Jacques PJ (2007) JOM 59:50

11. Terlinde G, Duerig T, Williams J (1983) Metall Mater Trans A 14:2101

12. Weiss I, Semiatin SL (1998) Mater Sci Eng A 243:46

13. Nag S, Banrjee R, Hwang JY, Harper M, Fraser HL (2009) Philos Mag 89:535

14. Zhao YQ, Xin SW, Zeng WD (2009) J Alloys Compd 481:190

15. Polmear IJ (2006) Light Alloys: From Traditional Alloys to Nanocrystals. $4^{\text {th }}$ eds, Elsevier, Amsterdam

16. Banerjee S, Mukhopadhyay P (2007) Phase Transformations: Example from Titanium and Zirconium Alloys. Elsevier, Amsterdam

17. Terlinde G, Rathien HJ, Schwalbe KH (1988) Metall Trans A 19A:1037

18. Jones NG, Dashwood RJ, Dye D, Jackson M (2008) Mater Sci Eng A 490:369

19. Zhang SZ, Liu ZQ, Wang GD, Chen LQ, Liu XH, Yang R (2009) J Cent South Univ Technol 16:354

20. Nakajima H, Ogasawara K, Yamaguchi S, Koiwa M (1990) Mater Trans JIM 31:249

21. Neumann G, Tuijn C (2008) Self-diffusion and Impurity Elements Diffusion in Pure Metals: Handbook of Experimental Data 14:149. Elsevier, Amsterdam

22. Gibbs GB, Graham D, Tomlin DH (1963) Philos Mag 8:1269

23. Lee SY, Iijima Y, Hirano KI (1991) Mater Trans JIM 32:451

24. Massalski TD, Okamoto H, Subramanian PR, Kasprzak L (Eds.) (1990) Binary Alloys Phase Diagrams, ASM International. Materials Park, $\mathrm{OH}$

25. Lenain A, Clement N, Veron M, Jacques (2007) Mater Sci Forum 539-543:3712

26. Li C, Wu X, Chen JH, Zwaag SV (2011) Mater Sci Eng A 528:5854

27. Yang YF, Luo SD, Schaffer GB, Qian M (2011) Mater Sci Eng A 528:6719

28. Ivasishin OM, Markovsky PE (1996) JOM 48:48 
List of the figures:

Figure 1: A schematic illustration of the thermo-mechanical processing schedule employed in the present study.

Figure 2: Back-scattered electron images of the as-sintered microstructures of (a) Ti-5Al-5Mo-5V-1Cr-1Fe (Ti-55511) and (b) Ti-5Al-5Mo-5V-2Cr-1Fe (Ti-55521) alloy. The $\alpha$ phase in Figure 2 (a) indicates inter-granular $\alpha$ and the $\alpha$ phase in Figure 2 (b) indicates intra-granular $\alpha$.

Figure 3: Back-scattered electron images of (a,c) Ti-55511 and (b,d) Ti-55521 alloys after (a,b) step I and (c,d) step II of the thermo-mechanical processing. White arrow in $(c, d)$ denotes the deformation direction.

Figure 4: Back-scattered electron images of (a,c,e) Ti-55511 and (b,d,f) Ti-55521 alloys after (a,b) step III, (c,d) step III(a) and (e,f) step IV of the thermo-mechanical processing. X in Figures (a,b) indicates the colony and Y in Figures $(\mathrm{a}, \mathrm{b})$ indicates the basket-weave morphologies. White arrows indicate the deformation direction.

Figure 5: Variation of the width of the grain boundary $\alpha\left(\alpha_{\mathrm{GB}}\right)$ phase with the thermo-mechanical processing steps. Step III(a) is not plotted in the above Figure due to its different parameters. The width of the grain boundary $\alpha$ after step III(a) is presented in the Tables 2 and 3 for both alloys.

Figure 6: X-ray elemental maps of Ti-55511 alloy after step IV corresponding to SEM image in (a) Ti, (b) Al, (c) Mo, (d) V, (e) Cr and (f) Fe.

Figure 7: X-ray elemental maps of Ti-55521 alloy after step IV corresponding to SEM image in (a) Ti, (b) Al, (c) Mo, (d) V, (e) Cr and (f) Fe.

Figure 8: Variation in grain boundary $\alpha$ phase $\left(\alpha_{\mathrm{GB}}\right)$ alloy composition with thermo-mechanical processing through Steps I to IV in: (a) Ti-55511 and (b) Ti-55521 alloys.

Figure 9: Variation in the $\alpha$ phase $(\alpha)$ alloy composition with thermo-mechanical processing through Steps I to IV in: (a) Ti-55511 and (b) Ti-55521 alloys.

Figure 10: Variation in $\beta$ phase ( $\beta$ ) alloy composition with thermo-mechanical processing through Steps I to IV in: (a) Ti-55511 and (b) Ti-55521 alloys. 
List of the Tables:

Table 1: The average composition of the as-sintered alloys determined by EDS (Energy Dispersive Spectroscopy).

Table 2: The amount of porosity, $\beta$ grain size and the various phases in the Ti-55511 alloy after thermo-mechanical steps.

Table 3: The amount of porosity, $\beta$ grain size and the various phases in the Ti-55521 alloy after thermo-mechanical steps.

Table 4: Diffusion rate of the alloying elements in $\alpha$ - and $\beta$-Ti at $1023 \mathrm{~K}\left(750^{\circ} \mathrm{C}\right)$.

Table 5: Solubility of the alloying elements in $\alpha$-Ti and $\beta$-Ti at $1023 \mathrm{~K}\left(750^{\circ} \mathrm{C}\right)$. 